This is a self-archived version of an original article. This version may differ from the original in pagination and typographic details.

Author(s): Salo, Markus; Pirkkalainen, Henri; Koskelainen, Tiina

Title: Technostress and social networking services : Explaining users' concentration, sleep, identity, and social relation problems

Year: 2019

Version: Accepted version (Final draft)

Copyright: (c) 2018 John Wiley \& Sons Ltd

Rights: In Copyright

Rights url: http://rightsstatements.org/page/InC/1.0/?language=en

Please cite the original version:

Salo, M., Pirkkalainen, H., \& Koskelainen, T. (2019). Technostress and social networking services : Explaining users' concentration, sleep, identity, and social relation problems. Information Systems Journal, 29(2), 408-435. https://doi.org/10.1111/isj.12213 
This is the final draft of the article accepted for publication in Information Systems Journal:

Salo, M., Pirkkalainen, H. \& Koskelainen, T. Technostress and social networking services:

Explaining users' concentration, sleep, identity, and social relation problems. Information Systems Journal, available online.

\title{
Technostress and Social Networking Services: Explaining Users' Concentration, Sleep, Identity, and Social Relation Problems
}

\begin{abstract}
It is common for users of social networking sites and services (SNS) to suffer from technostress and the various associated strains that hinder their well-being. Despite prior SNS stress studies having provided valuable knowledge regarding SNS stressors and their use consequences, they have not examined the various strains related to well-being that those stressors can create, nor the underlying SNS characteristics. To address this gap in the research, we employed a qualitative approach involving narrative interviews. As a contribution, our findings reveal four types of strains related to well-being (concentration problems, sleep problems, identity problems, and social relation problems) as well as two different patterns with distinct sets of SNS stressors and SNS characteristics that generate those strains. As practical implications, the findings of this study can help technostressed users to identify their strains, understand their underlying SNS characteristics and SNS stressors, and increase the possibility that they will be able to avoid the strains in the future.
\end{abstract}

Keywords: Technostress, social networking services, strains, stressors, IT characteristics.

\section{Introduction}

Social networking sites and services (SNS) have gained mass popularity and been incorporated into nearly all activities of life (Carter \& Grover, 2015; Maier et al., 2015b; Lin \& Lu, 2011). According to a report, people touch their smartphones 2617 times a day on average with SNS being the major contributor to the number (Dscout Research, 2016). SNS refer to online services that users employ to build and maintain social relations, for instance, by shared discussions, interests, and other activities (Luqman et al., 2017). ${ }^{1}$ Examples of currently popular SNS with hundreds of millions of active users include Facebook, Instagram, Twitter, and Snapchat (CNBC, 2017).

${ }^{1}$ In this study, we focus on the personal/leisure use of SNS that reflects non-organisational and non-work-related purposes. 
In addition to their benefits, the use of SNS can also result in serious negative side-effects for their users (Huffington Post, 2013; Krasnova et al., 2015; Maier et al., 2015a; 2015b, PBS Newshour, 2015). One major negative side-effect that decreases individual well-being is technostress (Fischer \& Riedl, 2017; Pirkkalainen \& Salo, 2016). Technostress is defined as stress that an individual experiences due to her/his use of information technology (IT) (Tarafdar et al., 2017). It comprises two main concepts: stressors (technostress creators) and strains (technostress outcomes). In the context of SNS, numerous users reportedly suffer from stress (Huffington Post, 2013; PBS Newshour, 2015) since SNS enable users, for example, to receive an on-going flood of push notifications and peek at the "glossified lives reported by other users" (New York Post, 2017; Krasnova et al., 2015).

A number of studies concerning SNS stress have identified various SNS stressors and their use consequences (Brooks et al., 2017; Laumer et al., 2013; Luqman et al., 2017; Maier et al., 2012a; 2012b; 2015a; 2015b). For instance, stressors such as SNS invasion, social overload, SNS disclosure, and SNS uncertainty have been found to be linked with use consequences including SNS (dis)satisfaction and (dis)continuance. However, these prior studies have been limited in (at least) two ways: 1) they have not detailed the potential strains related to users' well-being (e.g., concentration problems and social relation problems) that derive from such SNS stressors and 2) the technological characteristics of SNS that trigger the SNS stressors have not been identified. Thus, an explanation of how the technological characteristics of SNS contribute to the SNS stressors and, subsequently, to the users' well-being strains should serve to extend our current understanding.

To address this dearth of knowledge, our study attempts to answer the following research questions: 1) What types of well-being strains do the SNS users suffer from? 2) How are the different types of strains derived from their underlying SNS stressors and SNS characteristics? Answering these questions is important for the following reasons: practitioner reports highlight that users are at high risk of suffering from various well-being strains related to the personal/leisure use of SNS (Pew Research Center, 2016; The Guardian, 2017; The Happiness Research Institute, 2015); promoting well-being is considered a priority; and researchers can understand "the root causes" of SNS stress only by identifying the stress-inducing technological characteristics (Ayyagari et al., 2011, 849). To answer the research questions, we employed a qualitative approach involving narrative interviews. Such an approach is considered useful for deriving a variety of insights into previously uncovered topics, linking IT characteristics with users' (stress) experiences, and generating context-specific explanations for real-life IT use (Klein \& Myers, 1999; Venkatesh et al., 2013).

As a theoretical contribution, our findings go beyond the prior studies on SNS stress by uncovering four well-being strains for the previously known SNS stressors and exploring the unmapped area of stressor-triggering SNS characteristics. We also identify two distinct patterns with different sets of SNS stressors and SNS characteristics that contribute to different well-being strains. As practical implications, the findings of this study can help technostressed users and their stakeholders (e.g., families, friends, and health organisations) to identify well-being strains, understand their roots, 
and mitigate them. Such reduction of strains can benefit individuals and societies by increasing well-being and reducing healthcare costs (Ayyagari et al., 2011; Maier et al., 2015b; Srivastava et al., 2015).

The rest of the article is structured as follows: First, we present our research framework and review prior technostress studies according to it. Second, we describe and justify the methodology used in our empirical study. Third, we report the results of our empirical study. Finally, we present theoretical and practical implications, limitations, future topics, and conclusions.

\section{Theoretical Background}

\section{Research Framework}

Technostress depicts a "modern disease" that harms individuals' well-being in the workplace as well as the home (Brod, 1982). Technostress researchers have drawn from stress literature to understand the phenomenon. We apply the technostress framework by Ayyagari et al. (2011) as a basis of our study for the following reasons: First, it is based on the two main concepts of stress (stressors and strains) that have been established and found useful in stress research across various disciplines (Cooper et al., 2001; Lazarus, 1966; Lazarus \& Folkman, 1984). Second, the framework complements these two main concepts with an explicit instantiation of the IT artifact (IT characteristics) that can help IS researchers to uncover unique findings and emphasise the role of IT such as SNS (Orlikowski \& Iacono, 2001; Sarker et al., 2013). Third, the use of such a broad framework sensitises us to the theoretically important constructs but, at the same time, allows us to pay attention to the specific aspects of SNS use (Klein \& Myers, 1999).

The framework by Ayyagari et al. (2011) integrates stress and IS literature and is based on the idea that IT characteristics contribute to the formation of IT-related stressors, which subsequently contribute to strains of IT use (Figure 1). It depicts that the characteristics of a particular IT can trigger the appearance of environmental demand conditions and stimuli related to IT use (stressors). In line with previous research, the framework further presents that stress is created when these demands encountered by an individual exceed the individual's resources for dealing with them (Cooper et al., 2001; Lazarus, 1966; Lazarus \& Folkman, 1984). The latter part of this transaction is comprised of the individual's responses and outcomes in relation to the stressors (strains). The overall transaction regarding these concepts is referred to as stress (Ayyagari et al., 2011; Cooper et al., 2001; Lazarus, 1966; Lazarus \& Folkman, 1984). The concepts of the framework are defined as follows (Ayyagari et al., 2011):

- IT characteristics refer to (a user's perception of) the features and attributes of a particular IT.

- Stressors refer to the stress-creating stimuli encountered by the user.

- Strains refer to the user's responses and outcomes in relation to the stressors. 


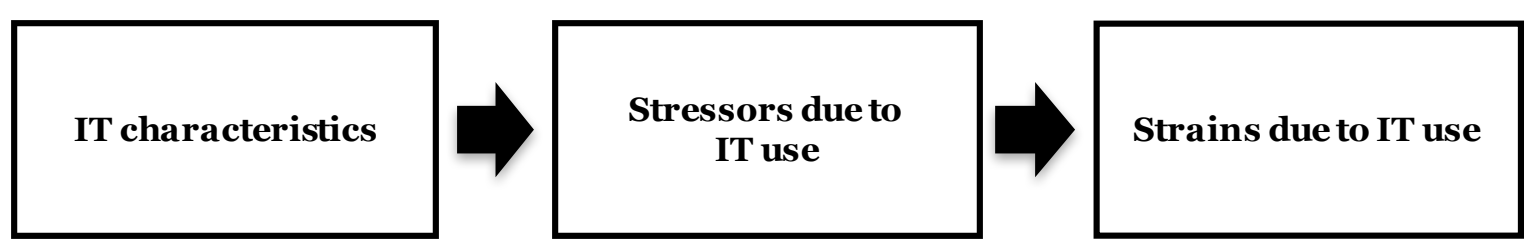

Figure 1. Technostress framework by Ayyagari et al. (2011)

For example, a constant flood of push notifications as sounds and messages from an SNS can create overload that exceeds the user's resources for dealing with it. Subsequently, overload can generate strains such as distracted concentration. Based on the person-environment fit model of stress (Edwards \& Cooper, 1988; 1990), the reason why stress occurs in such situations is explained by the imbalance between a person and their environment (Ayyagari et al., 2011). Stress occurs when there is a (significant) misfit between the person and the environment, such as the person's inability to deal with the stressors of the environment. Importantly, Lazarus $(1966,1993)$ highlights that stress occurs because of the individual's perception of the stressors. Thus, stress is subjective and two individuals can perceive a similar situation in a different manner.

\section{Prior Studies on Technostress}

We review prior studies on technostress to position them according to the technostress framework by Ayyagari et al. (2011)2. The findings of the prior studies related to SNS stress are summarised in Table 1, while the findings of the technostress studies focusing on contexts other than SNS are summarised in the Appendix.

A majority of the technostress studies has focused on the work and organisational context (e.g., Ayyagari et al., 2011; Ragu-Nathan et al., 2008; Salanova et al., 2013; Tarafdar et al., 2007; 2011; 2015; Wang et al., 2008). Researchers have studied technostress experienced by employees across various industries (e.g., Shu et al., 2011), amongst sales professionals (e.g., Tarafdar et al., 2015), and workers in specific contexts such as librarians (e.g., Ahmad et al., 2012). While studies have examined a wide variety of work-related IT devices and their applications altogether (e.g., Ayyagari et al., 2011), some have specifically investigated a particular type of IT, such as the mobile phone (e.g., Hung et al., 2011; 2015). Studies on work-related technostress have concluded that work IT can cause technostress due to stressors such as work/home conflicts and job insecurity (Ayyagari et al., 2011). They, in turn, can bring about strains such as reduced productivity, decreased organisational commitment, declines in innovation, and even work burnout (Ragu-Nathan et al., 2008; Srivastava et al., 2015; Tu et al. 2005).

Technostress, however, can be different in organisational/work and in personal/leisure use contexts. While many IT may be applied for both contexts, personal/leisure use differs from

\footnotetext{
${ }^{2}$ We followed the general suggestions of Webster and Watson (2002). We first searched for technostress-related articles published in the IS baskets of eight journals (AIS, 2011). We looked through each issue published between 1995 and 2017 and included articles that referred to technostress or IT-related stress in their titles or abstracts. In order to include articles published in other outlets and fields, we conducted citation searches and ran keyword searches. While every review may "miss some articles" (Webster \& Watson, 2002, p. xvi), we aimed to ensure that our searches resulted in an appropriate overview of the empirical technostress research. We then analysed each article according to the framework by identifying the IT characteristics, stressors and strains.
} 
organisational/work use because the former is fundamentally voluntary as users can, in principle, freely choose how they apply IT during their free time; users' own decisions, emotions, and responsibilities are highlighted; personal/leisure use tends to reflect hedonic experiences in addition to or instead of utility; and personal/leisure use is characterised with frequent and constant use occurrences throughout the day at home, work, and elsewhere (Kim et al., 2007; Venkatesh et al., 2012; Wu \& Lu, 2013). Recently, technostress has been found to be an important issue with personal/leisure use of IT such as SNS (Luqman et al., 2017; Maier et al., 2015a; 2015b).

Table 1. Summary of Prior Studies on SNS-related Stress.

\begin{tabular}{|c|c|c|c|c|}
\hline Article & Context & IT Characteristics & Stressors & Strains and outcomes \\
\hline $\begin{array}{l}\text { Brooks et al. } \\
2017\end{array}$ & $\begin{array}{l}\text { Personal / org: } \\
\text { SNS at work }\end{array}$ & - & $\begin{array}{l}\text { Distraction and IT } \\
\text { stressors: overload, } \\
\text { invasion, complexity, } \\
\text { insecurity, uncertainty }\end{array}$ & Internet addiction \\
\hline $\begin{array}{l}\text { Hsiao et al. } \\
2017\end{array}$ & $\begin{array}{l}\text { Personal / } \\
\text { leisure: SNS }\end{array}$ & - & Compulsive use & Technostress \\
\hline $\begin{array}{l}\text { Laumer et al. } \\
2013\end{array}$ & $\begin{array}{l}\text { Personal / } \\
\text { leisure: SNS }\end{array}$ & $\begin{array}{l}- \\
\text { (Number of friends } \\
\text { and content) }\end{array}$ & $\begin{array}{l}\text { Social interaction } \\
\text { overload }\end{array}$ & $\begin{array}{l}\text { SNS (dis)satisfaction; use } \\
\text { (dis)continuance }\end{array}$ \\
\hline $\begin{array}{l}\text { Luqman et al. } \\
2017\end{array}$ & $\begin{array}{l}\text { Personal / } \\
\text { leisure: SNS }\end{array}$ & - & Excessive use & $\begin{array}{l}\text { Technostress; } \\
\text { exhaustion; use } \\
\text { discontinuance }\end{array}$ \\
\hline $\begin{array}{l}\text { Maier et al. } \\
\text { 2012a }\end{array}$ & $\begin{array}{l}\text { Personal / } \\
\text { leisure: SNS }\end{array}$ & - & $\begin{array}{l}\text { SNS stressors: } \\
\text { uncertainty, invasion, } \\
\text { complexity, pattern, } \\
\text { disclosure }\end{array}$ & $\begin{array}{l}\text { SNS (dis)satisfaction; use } \\
\text { discontinuance }\end{array}$ \\
\hline $\begin{array}{l}\text { Maier et al. } \\
2015^{\mathrm{a}}\end{array}$ & $\begin{array}{l}\text { Personal / } \\
\text { leisure: SNS }\end{array}$ & - & $\begin{array}{l}\text { SNS stressors: } \\
\text { uncertainty, invasion, } \\
\text { complexity, pattern, } \\
\text { disclosure }\end{array}$ & $\begin{array}{l}\text { SNS exhaustion; use } \\
\text { discontinuance }\end{array}$ \\
\hline $\begin{array}{l}\text { Maier et al. } \\
2012 b\end{array}$ & $\begin{array}{l}\text { Personal / } \\
\text { leisure: SNS }\end{array}$ & - & Social overload & $\begin{array}{l}\text { SNS exhaustion; SNS } \\
\text { (dis)satisfaction; use } \\
\text { discontinuance }\end{array}$ \\
\hline $\begin{array}{l}\text { Maier et al. } \\
2015 \mathrm{~b}\end{array}$ & $\begin{array}{l}\text { Personal / } \\
\text { leisure: SNS }\end{array}$ & $\begin{array}{l}\text { - } \\
\text { (Extent of SNS usage } \\
\text { and number of } \\
\text { friends as usage } \\
\text { characteristics and } \\
\text { relationship type and } \\
\text { subjective social } \\
\text { support norm as } \\
\text { relationship } \\
\text { characteristics) }\end{array}$ & Social overload & $\begin{array}{l}\text { SNS exhaustion; SNS } \\
\text { (dis)satisfaction; use } \\
\text { discontinuance }\end{array}$ \\
\hline
\end{tabular}

Note: Only empirical findings are reported in the table.

Researchers have identified several SNS stressors, including SNS invasion, social overload, SNS disclosure, and SNS uncertainty (Brooks et al., 2017; Maier et al., 2012a; 2012b; 2015a; 2015b). SNS invasion refers to the overly central role played by SNS in an individual's life, while social overload reflects a perception of having to provide too much social support via SNS (Maier et al., 2015a; 2015b). SNS disclosure captures the abundance of information shared by oneself and others via SNS, while SNS uncertainty refers to a perception of being unsettled about constant SNS 
changes and updates (Maier et al., 2015a; 2015b). Subsequently, these SNS stressors can have consequences for SNS use, that is, they can increase SNS dissatisfaction, SNS exhaustion, use discontinuance, and addiction (Brooks et al., 2017; 2017; Maier et al., 2012a; 2012b; 2015a; 2015b). For example, researchers have demonstrated how SNS exhaustion mediates the relationship between the SNS stressors and the discontinuance of SNS use (Maier et al., 2015a). To complement these findings, researchers have concluded that excessive and compulsive use of SNS can, in general, result in stress experiences, exhaustion, and use discontinuance (Hsiao et al., 2017; Luqman et al., 2017). Finally, SNS usage and relationship characteristics, such as the number of friend relationships and the friend relationship types, can contribute to social (interaction) overload, which increases SNS dissatisfaction, exhaustion, and discontinuance intentions (Laumer et al., 2013; Maier et al., 2015a).

Despite these recent advancements in SNS stress and technostress research, there are (at least) two aspects that the prior studies have not yet addressed:

- First, prior research has studied work-specific strains and SNS use consequences but has not detailed users' potential well-being strains deriving from the SNS stressors. Importantly, stress generates well-being problems on both individual and social levels (Cooper et al., 2001; Tarafdar et al., 2015; Butler \& Gross, 2009). Individual well-being outcomes of stress include cognitive concentration and recovery or sleep problems (Greubel \& Kecklund, 2011; Lazarus \& Folkman, 1984; Sadeh et al., 2004), while social well-being outcomes comprise of one's conception of self and relations with others (Cooper et al., 2001; Lazarus \& Folkman, 1984; Thoits, 2013). These outcomes have not been covered in the prior literature, even though recent practitioner reports and news have argued that users have both individual and social problems due to SNS use: SNS use can distract users' cognitive concentration and sleep (The Guardian, 2017; The Happiness Research Institute, 2015) and enable negative changes in one's identity and social relations (Pew Research Center, 2016; The Happiness Research Institute, 2015). Studying these well-being strains is important for several reasons: it is the responsibility of IS researchers and IT designers to understand the diverse adverse outcomes of IT use (Lee, 2016); the relationship between IT and well-being problems (e.g., diseases and their management) is featured in one of the "exciting avenues for impactful IS scholarship" (Rai, 2016, iv); and it is the main aim of "the AIS grand vision of an [IT]-enabled bright society" to "eliminate the negative side-effects" of IT use such as the individual and social problems (Lee, 2015, iii).

- Second, it has remained unknown which technological characteristics of SNS (or other personal/leisure IT) contribute to the SNS stressors and, subsequently, to the individual and social strains. Such lack of knowledge "black boxes the technostress phenomenon, making the boundaries and relationship between technology characteristics and stress ambiguous" (Ayyagari et al., 2011, 832). Therefore, identification of the SNS characteristics is important for pointing out the roots of SNS-related stressors.

In sum, Figure 2 illustrates the extant knowledge and the research gap in relation to the technostress framework by Ayyagari et al. (2011). Studying the two unknown aspects is deemed 
crucial because users' different types of well-being strains can be deliberately reduced only by identifying them and understanding their underlying SNS characteristics.

\section{SNS characteristics Stressors due toSNS use Strains due to SNS use}

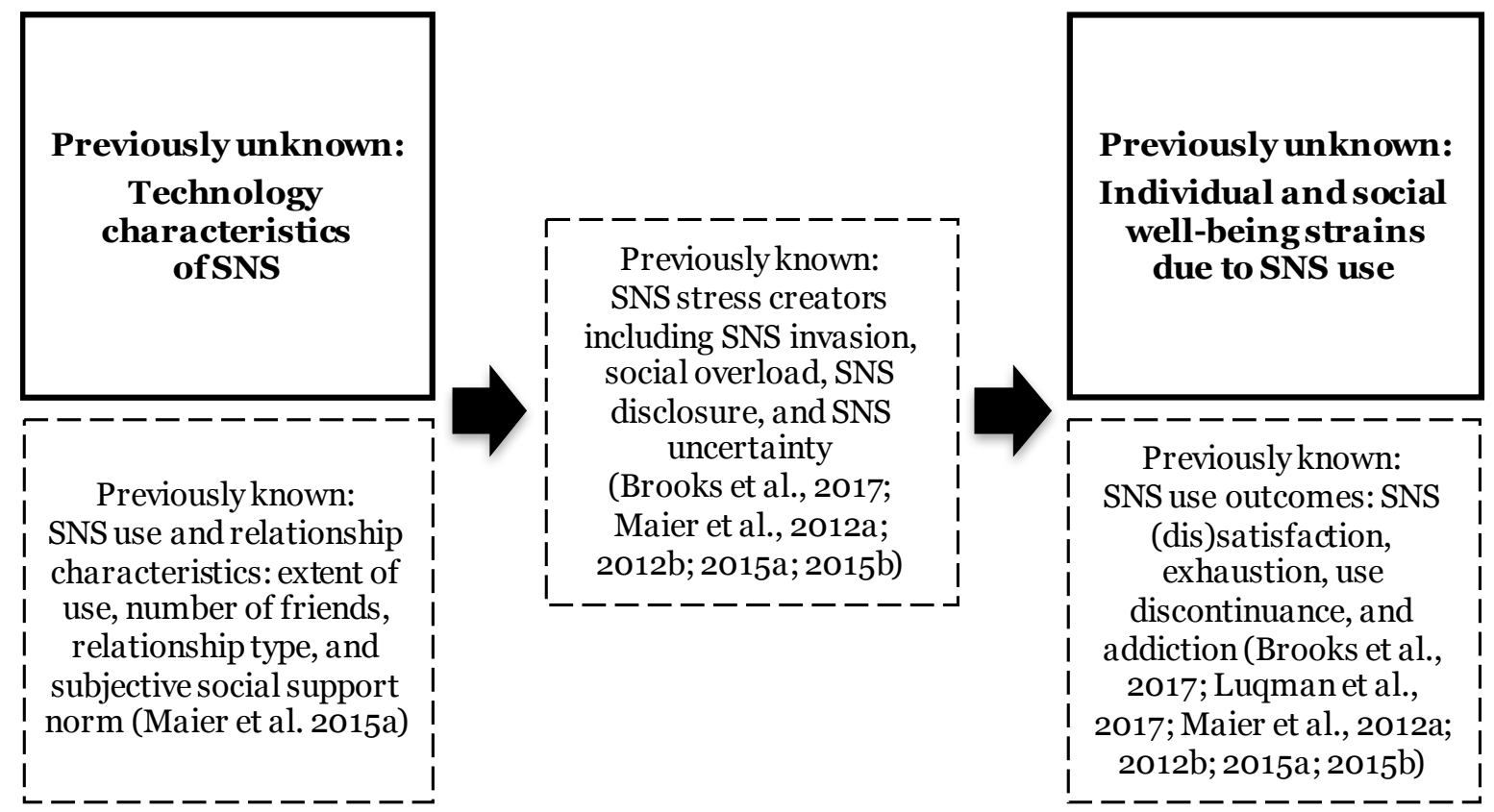

Figure 2. Illustration of the research gap and the focus of this study: Technostress framework by Ayyagari et al. (2011) complemented with extant SNS stress studies

\section{Method}

The aim of this study required detailed data about users' real-life experiences of SNS stress. Thus, we chose to utilise qualitative narrative interviews (Myers, 1997) to capture comprehensive descriptions of SNS-related strains, stressors, and characteristics from the user's point of view. This approach was deemed suitable since it enabled us to identify the strains that the SNS users suffer from and then to uncover the underlying reasons behind them. Such approaches have been found to be useful, since qualitative enquiries enable 1) the discovery of a variety of insights into previously uncovered topics, 2) the discovery of linkages between IT characteristics and user perceptions, and 3) the development of context-specific explanations of IT use as well as its consequences for real-life situations (Klein \& Myers, 1999; Venkatesh et al., 2013). Within the context of stress, researchers have encouraged others to employ ways of "asking people to provide narratives about stressful events" (Folkman \& Moskowitz, 2004, p. 750), since "the gold is in people's stories" (Folkman, 1999, p. xii).

\section{Data Collection}

We chose to collect data with narrative interviews to tap into the users' actual experiences of technostress related to SNS use. Researchers have found narratives useful for uncovering specific explanations of individuals' IT use and behaviour (Pentland, 1999; Schwarz et al., 2014). Narratives are descriptions of events that include a beginning, middle, and end and are best acquired from 
individuals who have directly experienced the studied phenomenon (Pentland, 1999; Schwarz et al., 2014). Thus, narratives enabled us to examine the users' perceptions about their strains and to trace the underlying reasons behind them. Importantly, this approach allowed the users to describe their experiences in their own words without being limited to the researchers' terminology (Gruen et al., 2002). We also could focus on the users' actual real-life experiences and avoid the risk of speculating about hypothetical use scenarios (van der Heijden, 2012).

Altogether, we interviewed 32 SNS users who had experienced SNS stress. We utilised purposeful sampling (Patton, 1990) by deliberately seeking users who would have first-hand experiences and relevant information regarding our research aims. Thus, we applied pre-screening to find potential subjects and gather brief spoken or written descriptions of their SNS stress: we harnessed networks and connections of connections to people who had referred to SNS stress; we used the snowballing technique to ask interviewees if they knew other potential subjects; we made an enquiry to the participants of an IS course about their technostress experiences; and we conducted an enquiry to the participant base of a municipal computer course for seniors. We applied the following inclusion criteria for this study: the interviewee had to 1) have used an SNS in their daily life (more than just testing), 2) have experienced stress related to their SNS use, and 3) possess the ability to remember and describe their experiences in detail. After identifying subjects satisfying these criteria, we made selections based on the "intensity" as estimated severity of the described technostress experiences (Patton, 1990, 171) and the guideline of "representing a variety of voices" to reach a diverse set of interviewees (Myers \& Newman, 2007, 22).

The interviews were conducted in 2015 and 2016. We started with interviews that focused on one popular SNS and continued by covering also other SNS. We expanded our coverage because we noted that restricting to only one SNS would result in a narrow view of SNS stress, it exposed us to the risk of missing essential insights deriving from other SNS, and SNS stress could derive from a joint effect of several SNS (e.g., push notifications from many SNS). We estimated that these benefits outweighed the potential reduction in particularity of the findings. The interviews included references also to other personal/leisure uses of IT such as gaming and reading news sites, which were excluded from the scope of this study.

Half of the interviewees were women and half were men. Their age ranged from 20 to 80 years. The interviewees were Finnish and varied in terms of their IT use experience. Altogether, they had varying occupational statuses, including employed, unemployed, student, and retired. All interviewees had used profile-based SNS such as Facebook, Twitter, or Instagram. Thirty of them had also applied other SNS that focus more on instant messaging functions, such as Whatsapp, Skype, or Snapchat. Twenty-nine interviewees had frequently applied their smartphone to access SNS, while three used SNS only on a computer. Thirty interviewees logged in to the SNS on a regular basis (e.g., daily), while two elderly users engaged in SNS activities occasionally.

We employed an open structure for the interviews to uncover real-life narratives. To contextualise our data (Klein \& Myers, 1999), we asked each interviewee to describe their background, as well as what types of IT they generally use, for what purposes, and to what extent. Regarding the aim of 
this study, we asked the interviewees, for example, to identify their problems arising from SNS use, as well as to thoroughly describe how and why their problems and stressful situations with SNS had originated and affected them. With each interviewee, we asked several detailed questions about their real-life examples, practices, and perceptions. As a result, we had narratives that described not only the users' strains, but also their underlying SNS stressors and SNS characteristics.

We followed the main guidelines of interviewing set by Myers and Newman (2007). For example, we used techniques such as mirroring, showed empathy by careful reactions to the answers, and left room for flexible explorations of interesting themes that emerged during the interviews. We instructed the users to take time to think carefully about their past experiences and anchored questions in actual events to minimise recall bias. We continued data collection until a sufficient level of saturation had been reached, no essentially new information appeared to emerge, and the benefit from conducting further interviews was estimated to be marginal. The interviews lasted approximately 47 minutes, on average, and contained approximately 117,00o words on 386 pages. The interviews were recorded and transcribed for the relevant parts.

\section{Data Analysis}

In this study, the unit of analysis was the individual user's perception of technostress related to SNS use. We utilised the established guidelines and procedures for qualitative analysis presented by Berg (2004, 285-287): identify overarching categories (e.g., from literature); read data and establish data-driven categories; determine coding scheme and sort data according to it; search for patterns; and relate the findings with prior research. We describe these procedures in detail as follows.

As advised by Berg (2004), we first extracted three general categories from the technostress framework by Ayyagari et al. (2011) (Figure 1 refined to the SNS context: well-being strains due to SNS use, SNS stressors, and SNS characteristics). We then (re)read the data, placed relevant text portions (e.g., sets of words or sentences) under the three categories, and attached the text portions with descriptive labels within NVivo software. Examples of these labels include "others' unpleasant conversational conduct", "drawing unwanted attention in discussions", and "text misunderstanding". In the labelling, we utilised keywords from the data and conducted author checks to ensure that the labels matched the data. We then sorted similar labels with each other and attached them with descriptive category names. For example, the labels "others' unpleasant conversational conduct", "drawing unwanted attention in discussions", and "text misunderstanding" were combined into a stressor category of "online discussion conflict". To verify this sorting, we constantly compared the newly examined data with our previous codings and utilised multiple author checks, iterations, and sketches about the emerging categories. When available, we adopted concepts for category names from prior literature (see Table 1 and Appendix). Nine of our resulting 14 categories included new content that we could not identify from prior technostress studies (see Figures 3 and 4). Therefore, we attached the nine categories with names based solely on our data. The remaining five categories, however, included similar aspects that had been found in prior technostress and SNS stress studies and, thus, were named akin to 
them. As a result, we had developed our coding scheme that contained category names, descriptions, and examples for five SNS characteristics, five SNS stressors, and four well-being strains (see Table 2). We sorted the four strains further based on the two levels of well-being strains identified in stress literature: individual and social strains (Cooper et al., 2001; Tarafdar et al., 2015; Butler \& Gross, 2009).

Next, we focused on the recurrent patterns and relationships in the data (Berg, 2004; Miles \& Huberman, 1994). Informed by the technostress framework (Ayyagari et al., 2011), we paid attention to the users' strains of SNS use and traced the strains back to their causes. In practice, we went through the content of the text portions that were placed into strains one by one. We then examined which SNS stressors did each text portion reflect as the source of the strain and which SNS characteristics did trigger the corresponding SNS stressors. This was achieved by analysing the text of the strains and examining under which SNS stressors and SNS characteristics were the underlying sources of the strain coded. Although it may be impossible to identify exclusive paths that perfectly determine human behaviour, two distinctive patterns emerged: the individual strains were linked with different underlying SNS stressors and characteristics than social strains. These patterns are demonstrated with chains of evidence in Tables 3-6. Finally, we compared our findings with the prior technostress and SNS stress studies (illustrated in Figures 3 and 4 and elaborated in the Discussion section).

We aimed to ensure that our analysis was appropriate by adhering to the procedures by Berg (2004) and complying with the principles by Klein and Myers (1999): With the analysis process, we maintained the idea of the hermeneutic circle by moving back and forth between the interviewees' specific descriptions of SNS-related technostress experiences and the generic research framework by Ayyagari et al. (2011) delineating the three concepts of technostress. The framework provided an overarching lens for abstracting, generalising, and making sense of our detailed insights. Regarding triangulation, we ensured that the main insights recurred in multiple interviews. Regarding the researcher-subject interaction, we let the interviewees choose their stressful experiences to be reported and speak uninterruptedly using their own words. As the topic was sensitive, we aimed to appear empathetic, demonstrate understanding of the interviewees' negative experiences, and highlight that the research reports would not include names or other identifiers. According to our estimation, the interviewees reported their stressful experiences openly (e.g., they opened up about their personal weaknesses related to SNS use and described their problematic SNS use with curse words). Regarding multiple interpretations, we acknowledged that stress can be subjective and two individuals can perceive a similar situation differently (Lazarus, 1966; 1993). The results of our analysis are presented with detailed illustrations and examples from the data as follows.

\section{Results}

On a general level, our data indicated that technostress caused a reduction in the users' overall well-being. However, we deliberately wanted pay close attention to the specific well-being strains of SNS use. Thus, our analysis highlighted four categories of problems from which the SNS users suffered: concentration and sleep problems as individual strains and identity and social relation 
Table 2. Coding Scheme: Categories, descriptions, and examples from data.

\begin{tabular}{|c|c|c|}
\hline Category & Description & | Example from data \\
\hline $\begin{array}{l}\text { Strains due to SNS } \\
\text { use }\end{array}$ & \multicolumn{2}{|c|}{ The user's responses and outcomes in relation to the stressors } \\
\hline $\begin{array}{l}\text { Concentration } \\
\text { problems }\end{array}$ & $\begin{array}{l}\text { The interference of SNS in } \\
\text { focusing on a situation at } \\
\text { hand }\end{array}$ & $\begin{array}{l}\text { "[Due to SNS] I have to abandon whatever I am } \\
\text { doing and shift my attention away [to the SNS]." }\end{array}$ \\
\hline Sleep problems & $\begin{array}{l}\text { The disturbance of nightly } \\
\text { SNS use on sleeping }\end{array}$ & $\begin{array}{l}\text { "I'll notice when someone communicates at } 4 \text { AM so } \\
\text { that there's something going on... I might reply in } \\
\text { the middle of the night if something comes up." }\end{array}$ \\
\hline Identity problems & $\begin{array}{l}\text { The SNS-induced tension } \\
\text { related to conception of } \\
\text { oneself vis-à-vis others }\end{array}$ & $\begin{array}{l}\text { "The other users' status updates and posts have an } \\
\text { effect on my self" }\end{array}$ \\
\hline $\begin{array}{l}\text { Social relation } \\
\text { problems }\end{array}$ & $\begin{array}{l}\text { The SNS-induced harm to } \\
\text { one's interaction with } \\
\text { others }\end{array}$ & $\begin{array}{l}\text { "So, an actual war breaks out [in a dog breed group } \\
\text { on an SNS]." }\end{array}$ \\
\hline SNS stressors & \multicolumn{2}{|c|}{ Stress-creating SNS stimuli encountered by the user } \\
\hline SNS overdependence & $\begin{array}{l}\text { The immoderate reliance } \\
\text { on SNS in behaviour and } \\
\text { daily activities }\end{array}$ & $\begin{array}{l}\text { "[Smartphones and SNS] are so totally integrated to } \\
\text { people's life that it doesn't feel like usage anymore } \\
\text { but rather an extension of oneself. Even with me." }\end{array}$ \\
\hline Overload & $\begin{array}{l}\text { The confrontation with } \\
\text { excessive information, } \\
\text { technology, or social } \\
\text { support requests }\end{array}$ & $\begin{array}{l}\text { "I'll drown if I go along with all of the [information] } \\
\text { flows." }\end{array}$ \\
\hline $\begin{array}{l}\text { Life comparison } \\
\text { discrepancy }\end{array}$ & $\begin{array}{l}\text { The discomfort when } \\
\text { contrasting one's life to } \\
\text { the lives of others via SNS }\end{array}$ & $\begin{array}{l}\text { "It's probably like that I start to compare myself } \\
\text { [and my life] to the others and that kind of stuff." }\end{array}$ \\
\hline $\begin{array}{l}\text { Online discussion } \\
\text { conflict }\end{array}$ & $\begin{array}{l}\text { The disputes between two } \\
\text { or more SNS users }\end{array}$ & $\begin{array}{l}\text { "Sometimes a dispute or discussion arises and I } \\
\text { really need to go over and over with people to try to } \\
\text { quiet down the situation." }\end{array}$ \\
\hline $\begin{array}{l}\text { Privacy and security } \\
\text { uncontrollability }\end{array}$ & $\begin{array}{l}\text { The low possibility to } \\
\text { control personal } \\
\text { information on SNS }\end{array}$ & $\begin{array}{l}\text { "I think [using a particular SNS] is more or less } \\
\text { unpleasant. I have doubts about whether I forfeit my } \\
\text { information when I use [the SNS]." }\end{array}$ \\
\hline SNS characteristics & \multicolumn{2}{|c|}{ (The user's perception of) the features and attributes of SNS } \\
\hline $\begin{array}{l}\text { Push notification } \\
\text { features }\end{array}$ & $\begin{array}{l}\text { The automated SNS alerts } \\
\text { that deliver information }\end{array}$ & $\begin{array}{l}\text { [On a particular SNS]: "I've set that if someone from } \\
\text { a certain group of persons tweets, then [the } \\
\text { application] beeps." }\end{array}$ \\
\hline $\begin{array}{l}\text { Multipurpose } \\
\text { functionality }\end{array}$ & $\begin{array}{l}\text { The ability of SNS to } \\
\text { afford various use } \\
\text { purposes }\end{array}$ & $\begin{array}{l}\text { "II use an SNS] to stay in touch with people and look } \\
\text { at the photos other people post. And to check all of } \\
\text { the events." }\end{array}$ \\
\hline $\begin{array}{l}\text { Real-time information } \\
\text { renewability }\end{array}$ & $\begin{array}{l}\text { The regeneration of } \\
\text { personalised SNS posts, } \\
\text { updates, and other data }\end{array}$ & $\begin{array}{l}\text { "A whole lot of stuff arrives constantly at my } \\
\text { newsfeed. I'm in a few international groups with } \\
\text { thousands of users, which generate terrible amounts } \\
\text { [of information]." }\end{array}$ \\
\hline Self-disclosure features & $\begin{array}{l}\text { The functions that allow } \\
\text { revealing information } \\
\text { about oneself }\end{array}$ & $\begin{array}{l}\text { "I use [a particular] SNS to share my pictures and } \\
\text { things like that." }\end{array}$ \\
\hline $\begin{array}{l}\text { Information cue } \\
\text { paucity }\end{array}$ & $\begin{array}{l}\text { The partiality and lack of } \\
\text { contextual richness in } \\
\text { SNS data }\end{array}$ & $\begin{array}{l}\text { "[With SNS] it's about selectively choosing [the most } \\
\text { fitting] portions of one's life. Like showcasing that } \\
\text { 'this is the life I live' but it doesn't show all of it." }\end{array}$ \\
\hline
\end{tabular}


problems as social strains. While these problems may result from a combined effect of several factors, our data demonstrates how SNS use can be one contributor to them. According to our data, the social strains and individual strains were derived from a different set of SNS stressors and characteristics. As such, our data reflected two patterns of SNS characteristics, stressors, and strains: one pattern for individual strains and another pattern for social strains. In the following sections we elaborate upon the two patterns with quotations from the interviewed users in italics.

\section{Pattern 1 Strains: Concentration and Sleep Problems}

An individual strain pertaining to twenty interviewees was concentration problems: the negative effect of SNS use on users' ability to concentrate on a situation or a task at hand (chain of evidence: Table 3). These users reported this was because their SNS use frequently distracted their attention and made it harder to concentrate on a specific issue at hand or even just "live in the moment". A recurring situation was that the SNS draw the users' attention away from the formal or informal daily activities upon which they were supposed to focus (e.g., such as studying or having a discussion with spouse). These interviewees described how they felt their attention span had become weaker and shorter due to frequent SNS use. Simultaneously, they described that they had become increasingly "restless". For example, one of the interviewees narrated how his use of a particular SNS had drained his concentration abilities:

"For instance, with [a particular SNS] I realised that whether it's day or night, I spend an awful lot of time with it. ...I started to feel like I'm becoming a zombie. ...I realised how much time and the certain type of thinking capacity, or whatever it is, it took from me. And so I couldn't properly concentrate on my studies and that kind of activity."

The concentration problems were considered severe, as the interviewees described how they failed to manage their daily duties, enjoy their life to the fullest, and get the most out of themselves. For example, one of the interviewees blamed SNS for stealing his attention and compared losing attention to losing a concrete thing:

"What I experience as the most nerve-racking thing, and I notice my frustration coming from... When I want to concentrate on something I'm doing... or when I'm in an awesome 'flow' state. ...[then] a darn [SNS] message pops up and I lapse to read it. And yet another [social] app is about to yell shortly. ...I lose the moment. And the time is gone. It steals. It takes that room that belongs to us or to [me]. ... and these are very powerful feelings. It could be compared to a situation when I lose an actual and concrete thing."

Another individual strain of SNS use was sleep problems: the disturbance of nightly SNS use on sleep (chain of evidence: Table 4). According to our data, the disturbance was based mainly on the considerable amount of time spent on SNS that was cut away from sleeping time. All interviewees had used SNS when in bed, for instance, as the last thing before falling asleep or the first thing after waking up. Six interviewees described definite instances of sleep problems due to SNS by using terms such as "sleep problems", "sleep difficulties", and "changes in sleep" when talking about latenight SNS surfing: 
"It was happening like, I went to bed, and when I was just about to sleep, I heard a beep [as an SNS notification] or something. ...[I experienced] sleep problems, particularly at the time I used [SNS via smartphone] very much at night. ...for several years, I kept the smartphone in my bed, but then I decided that it is not wise anymore to mess around with it after 10 PM or especially when I try to sleep. I think [SNS and the smartphone] comprised a quite clear contributor [to my sleep challenges].”

Particularly, these six interviewees perceived that their late-night SNS surfing concretely harmed sleep quality, timing, and duration. They felt that their SNS use ate a portion of their potential sleep time per night and, at times, they were awakened by the sounds and lights triggered by SNS. For example, one interviewee believed that his late-night SNS use had an influence on falling asleep and sleep quality:

"I can't use it [anymore] at night right before going to sleep. I noticed that my sleep and resting [were impacted]... So that I have to stop using after 9 PM. Especially staring at [SNS via my smartphone] in bed at night. I've now quit it completely, once I observed that it influences my sleep seriously much. ...it influences falling asleep and how fast I can get to deep sleep. It affected those two things."

\section{Pattern 1 Stressors: SNS Overdependence and Overload}

In the interviewees' narratives, both of the individual strains can be traced back to two types of stressors: SNS overdependence and the constant feeling of SNS overload. By SNS overdependence, we refer to the users' high reliance on SNS in their behaviour and daily activities ${ }^{3}$. The interviewees emphasised how their concentration and sleep were hindered, particularly because SNS was present in nearly all aspects of their life, SNS dominated some of their daily activities (especially bedtime activities), and they were too accustomed to using SNS all the time. These aspects increased the users' tendency to frequently switch their attention from other activities to SNS as well as to stay awake past their bedtime. SNS and technology overdependence is illustrated by the following quotes:

"Unfortunately, it really dominates, governs, and controls my day quite significantly. Like when I wake up to the beeping sounds of my smartphone in the morning. And when I'm going to sleep, I gaze at the screen as the last thing at night and see how many new followers I got on my [SNS] accounts."

"At times I feel it's a bit too much. So I could restrict [my use of a particular SNS] a little. So that I wouldn't have to hold my smartphone all the time... It interferes with my attention for studying every now and then... When reading on an exam, doing some tasks and other things like those."

${ }^{3}$ Dependence is different from addiction in that dependence is a broader term; it emphasises users' reliance on SNS in daily activities and does not necessarily indicate compulsive behaviour. 
Table 3. Example chain of evidence: Concentration problems

\begin{tabular}{|c|c|c|c|}
\hline Interviewee & IT Characteristics & Stressors & Strains \\
\hline $\begin{array}{l}\text { Lynn, Woman, } 31 \\
\text { - Entrepreneur, } \\
\text { part-time } \\
\text { student, mother } \\
\text { - Has used a } \\
\text { particular SNS } \\
\text { since 2006 } \\
\text { - Uses the SNS } \\
\text { "completely all } \\
\text { the time”, "it's } \\
\text { always on } \\
\text { hand" } \\
\text { - Applies it } \\
\text { mainly on a } \\
\text { smartphone } \\
\text { - Writes status } \\
\text { updates or } \\
\text { comments } \\
\text { "several times a } \\
\text { day" }\end{array}$ & $\begin{array}{l}\text { "[A particular SNS] always } \\
\text { notifies me... Notifications and } \\
\text { all arrive on a daily basis and } \\
\text { quite a lot." (coded to Push } \\
\text { notification features) } \\
\text { "I use [the SNS] for absolutely } \\
\text { everything: to stay in touch } \\
\text { with my friends and for my } \\
\text { own company... I update what } \\
\text { has happened to me and post } \\
\text { [news] articles... I've played } \\
\text { games on it... I'm in parents' } \\
\text { peer support and pen pal } \\
\text { groups... And in flea market } \\
\text { groups." (coded to } \\
\text { Multipurpose } \\
\text { functionality) } \\
\text { "[The newsfeed] updates with } \\
\text { so much information that } \\
\text { some of it I can't even keep } \\
\text { track of... And if I start to read } \\
\text { all of stuff at my [newsfeed], } \\
\text { then I'll notice that a couple of } \\
\text { hours has gone by like oops." } \\
\text { (coded to Real-time } \\
\text { information renewability) }\end{array}$ & $\begin{array}{l}\text { "If I face a situation [without } \\
\text { Internet access] and I'm not } \\
\text { prepared for it, I'm a bit like, } \\
\text { help! What's happening now? } \\
\text {...[I'm using the SNS] always, } \\
\text { like when I wait for a bus... sit } \\
\text { on a bus stop or in a bus... I tend } \\
\text { to do it eventually when I have } \\
\text { any spare time... And it happens } \\
\text { easily in situations when I'm } \\
\text { supposed to focus on something } \\
\text { else...It's almost like an } \\
\text { instinctive reaction that I don't } \\
\text { think about too much." (coded to } \\
\text { SNS overdependence) } \\
\text { "[The flow of push notifications] } \\
\text { distracts me... I receive quite a } \\
\text { lot of [notifications] even I } \\
\text { wouldn't have to know all those } \\
\text { things at that particular } \\
\text { minute... Like if someone else } \\
\text { comments something } \\
\text { somewhere... I've though about } \\
\text { removing [the SNS] app from } \\
\text { my phone so that [the } \\
\text { notifications] wouldn't disturb } \\
\text { me all the time... At times I feel } \\
\text { it's a bit too much." (coded to } \\
\text { Overload) }\end{array}$ & $\begin{array}{l}\text { "It interferes with my } \\
\text { attention for studying every } \\
\text { now and then... For example, } \\
\text { the phone is next to me and } \\
\text { vibrates [due to the SNS] all } \\
\text { the time when I'm writing... } \\
\text { When reading on an exam, } \\
\text { doing some tasks and other } \\
\text { things like those. At times, if it } \\
\text { gets out of the hand, like I get } \\
\text { distracted and check some } \\
\text { thing [on an SNS], I later } \\
\text { notice that an hour passed by } \\
\text { as I read something } \\
\text { completely irrelevant. So yes, } \\
\text { it harms me in a way. I know } \\
\text { that I have a hard time } \\
\text { concentrating sometimes even } \\
\text { without [the SNS] but } \\
\text { especially with it." (coded to } \\
\text { Concentration problems) }\end{array}$ \\
\hline
\end{tabular}

Note: The textual excerpts in Tables 3-6 can include codings also to other categories than the one mentioned.

Table 4. Example chain of evidence: Sleep problems

\begin{tabular}{|c|c|c|c|}
\hline Interv & IT Characteristics & Stressors & Strains \\
\hline $\begin{array}{l}\text { Matt, Man, } 29 \\
\text { - Software } \\
\text { developer } \\
\text { - Used various } \\
\text { SNS such as } \\
\text { microblogs and } \\
\text { blogs since } \\
2008 \\
\text { - Used to apply } \\
\text { various SNS } \\
\text { "throughout the } \\
\text { day" } \\
\text { - Applied them } \\
\text { on smartphones } \\
\text { and computers } \\
\text { - Has reduced } \\
\text { usage after } \\
\text { perceiving the } \\
\text { problems }\end{array}$ & $\begin{array}{l}\text { "[At the stressful times], it was } \\
\text { actually the prime of [social] } \\
\text { push notifications. The } \\
\text { smartphone could've been } \\
\text { beeping several times an hour. } \\
\text {...also during night." (coded to } \\
\text { Push notification features) } \\
\text { "I communicated with } \\
\text { friends... I browsed } \\
\text { [microblog and feeds] feeds... } \\
\text { I looked for stuff that interests } \\
\text { me." (coded to Multipurpose } \\
\text { functionality) } \\
\text { "It was wonderful technology } \\
\text { that I could receive real-time } \\
\text { stuff to my smartphone from } \\
\text { various [SNS applications and } \\
\text { feeds]." (coded to Real-time } \\
\text { information renewability) }\end{array}$ & $\begin{array}{l}\text { "I consumed [microblog and } \\
\text { blog] feeds... For several years, I } \\
\text { kept the smartphone in my } \\
\text { bed... Especially earlier, if I } \\
\text { didn't get to sleep, then I took } \\
\text { the smartphone to my hand, } \\
\text { which was not reasonable in } \\
\text { any certain way! ...[with SNS } \\
\text { feeds in general], it was always } \\
\text { like 'ooh, sweet, there's this and } \\
\text { that stuff around for me'." } \\
\text { (coded to SNS } \\
\text { overdependence) } \\
\text { "The information flood... it was } \\
\text { stressful in a certain way... And } \\
\text { I recall that I sometimes checked } \\
\text { [at night] what [the incoming } \\
\text { SNS notifications] were about... } \\
\text { I don't [anymore] understand } \\
\text { people who are able to listen to } \\
\text { that constant beeping [of SNS } \\
\text { notifications]." (coded to } \\
\text { Overload) }\end{array}$ & $\begin{array}{l}\text { "Most of my usage was } \\
\text { probably nightly and, for } \\
\text { example, just before going to } \\
\text { bed I was like I'll check that } \\
\text { thing quickly... It was } \\
\text { happening like, I went to bed, } \\
\text { and when I was just about to } \\
\text { sleep, I heard a beep [as an } \\
\text { SNS notification] or } \\
\text { something... [I experienced] } \\
\text { sleep problems, particularly } \\
\text { at the time I used [SNS via } \\
\text { smartphone] very much at } \\
\text { night. I think [SNS and the } \\
\text { smartphone] comprised a } \\
\text { quite clear contributor [to my } \\
\text { sleep challenges]." (coded to } \\
\text { Sleep problems) }\end{array}$ \\
\hline
\end{tabular}


By overload, we refer to the users' confrontation with excessive amounts of information, technology, or social support requests4. The interviewees emphasised how users are continuously challenged by the on-going flow of information derived from multiple sources (e.g., various SNS channels) and that require various types of actions. Overload caused the users to constantly shift from one target of attention to another. Such multi-focus not only hindered the interviewees' much-needed concentration abilities, but also their sleep since it was perceived as an unfavourable state to fall asleep. The interviewees reported that overload reflected a feeling of being overwhelmed in a negative sense or having too much to process in their head. For example, one interviewee described his daily feelings of overload as follows:

"Most of all, I think it's about the information abundance where I live, so that the [information] comes from all places and to all channels. From all people. It's probably what I feel is the most negative issue. It's almost daily. ...and then I can't reach the presence that I'd need for a particular situation at hand."

\section{Pattern 1 SNS Characteristics: Push Notification Features, Multipurpose Functionality, and Real-Time Information Renewability}

The characteristics that contributed to SNS overdependence and overload include push notification features, the multipurpose functionality of SNS, and information renewability. Each of the characteristics had their own ways of contributing to SNS overdependence and overload.

First, push notification features refer to the functions of SNS that automatically input information feeds to the user whenever new information is available (e.g., notification sounds and visuals from new messages). They concretely enabled SNS overdependence and overload because they maintained the continuous interaction between the user and the SNS and increased the amount of information received by the user. More precisely, the interviewees highlighted that the arriving push notifications persuaded them to increase the occasions of SNS use, strengthened their personal connectedness to SNS, and constituted a major information flow from SNS. The interviewees rather automatically checked what their push notifications were about. They admitted that checking notifications had developed into a dependency for them and that the notifications brought more information than what they would have liked to receive. Our data indicated that the unforeseen and random timing of the push notifications made a difference, since push notifications were less disturbing if the users could prepare for receiving them. Realistically, always being prepared for push notifications is highly difficult as SNS often pushes information to the users at any random time. Typical cases are demonstrated by the following examples:

"[My smartphone] is nowadays really like ding, ding, ding. I immediately hear when someone posts or updates something [on a particular SNS]. Therefore, I ever so often think that it's a danger and it's getting out of hand."

"I had some sleep problems. ...I remember when I was just about to fall asleep, I heard a stirring beep... And for example, after reinstalling [a particular SNS] all of my

4 In the literature, different types of overload, including information, technology, and social overload, are referred to. In this study, we refer to a combination of these types because they often appeared to be intertwined in the interview narratives. 
notification settings were [automatically] turned off. So, like after about 10 minutes, my smartphone was completely full [of notifications from the particular SNS]. And, to be honest, I got pissed off about it! ...that situation made me think, like, damn, those [flooding notifications] are just absolutely horrific!"

Second, the interviewees concluded that the multipurpose features, which allow individuals to use SNS for various purposes, increased their overdependence and overload. Opposed to only one use purpose, multipurpose features enabled the interviewees to integrate SNS into many aspects of their lives (e.g., keeping in touch with friends, reading news, playing games, arranging and attending events). As a result, the interviewees described how SNS had become a primary hub for their activities and how their behaviours and routines had become increasingly dependent on them. Additionally, as the purposes for what the SNS were used increased, so did the amount of information, channels, and activities. The following quotation illustrates how an interviewee used the various multipurpose features and how they had undesired consequences for her:

"[I use a particular SNS] to stay in touch with people and look at the photos other people post. And to check all of the events. I've every now and then thought that maybe I should quit using [the particular SNS], but it's such an easy way to find all upcoming events and other things. ...and I can edit my own profile page in so many ways. ...and when the front page shows me updates from all the people I follow and like, I just remain on [the site] to read those by clicking one link and then opening another link and so on....so I kind of feel like 'no way', how am I reading something like this again when I could do something else. ...it causes me a feeling of being kind of overloaded."

Third, the interviewees were prone to real-time information renewability as they were tempted by the possibility than new information could have been generated in the SNS since their previous login. This was particularly manifested via social information newsfeeds and chat discussions. The desire to browse through the latest updates in the newsfeeds and discussions created dependence and added the possibilities of "craving information and news". If one channel had already been thoroughly read, then the users could peek at another one to satisfy their thirst for new information. As such, the amount of received information grew. It was hard to resist the renewal of real-time information:

"In the evening before going to bed, it's like my fingers are itching and I feel like I must check [a particular SNS] once a day to see what [news] has happened in [the particular SNS]."

"[SNS] were calling me out all the time, like here you can find new things, things happen here, the world turns here. The temptation to check the [SNS] newsfeeds is so great that it consumes quite a lot of energy."

In sum, Figure 3 maps the SNS characteristics and SNS stressors behind the individual strains of SNS use. 


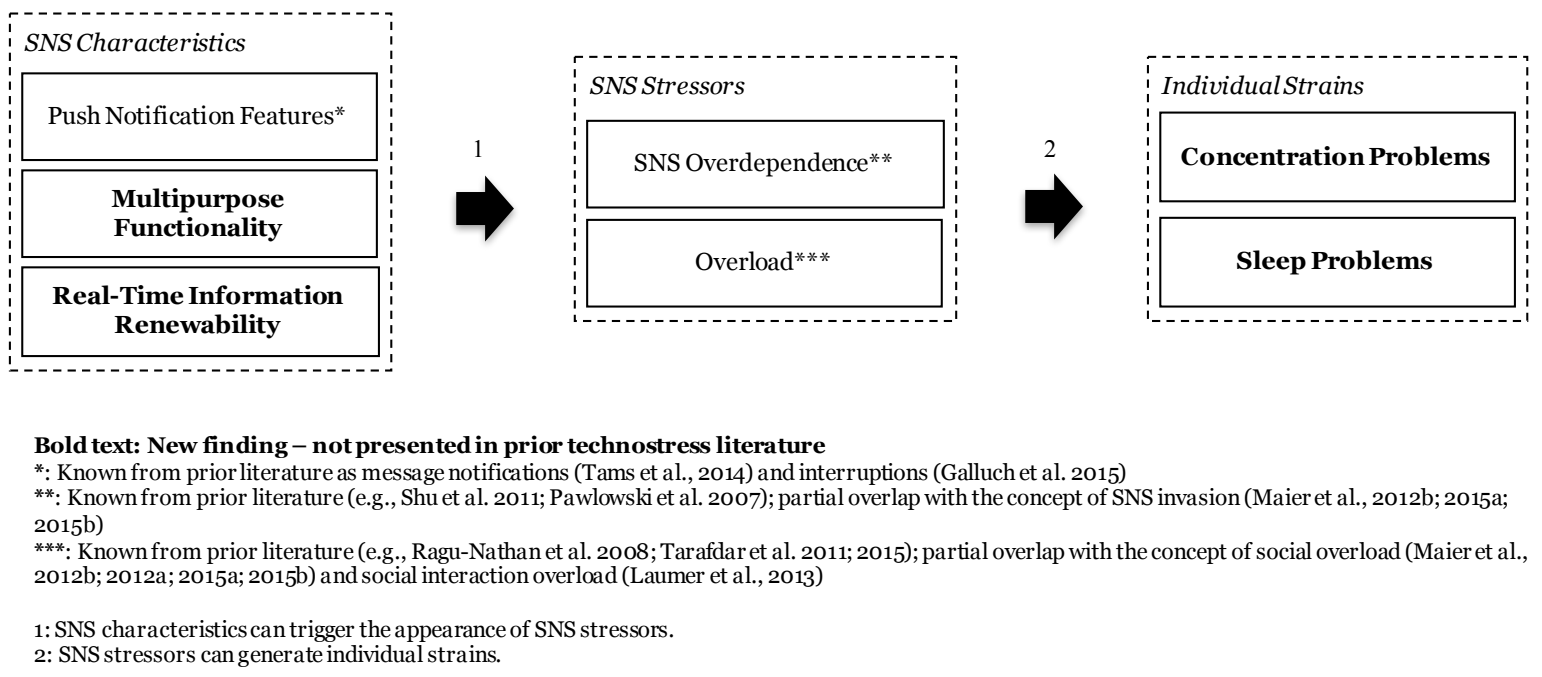

Figure 3. Pattern 1: SNS Characteristics and SNS Stressors Underlying Individual Strains

\section{Pattern 2 Strains: Identity and Social Relation Problems}

According to our data, SNS use can create strains tied closely to the users' social life. First of them is identity problems, by which we refer to the users' SNS-induced tensions related to their conceptions of themselves and communicating such conceptions to others (chain of evidence: Table 5). Sixteen interviewees highlighted how SNS use can derive a pressure to constantly question, and be reassured of, one's own activities. This is due to the SNS' unprecedented possibility of seeing glossy peeks of others' lives and posting updates about one's own life, which can cause a negative self-image and disappointment in one's own identity. Communications in SNS are socially evaluated in public, such as through the number of likes and comments. It can cause dilemmas, since such social evaluation pushes SNS users to constantly think whether or not their own life activities are socially favoured. These aspects can bring about identity pressures, as illustrated by the following excerpt from the data:

"If I think about [a particular profile-based SNS] and also other [SNS]. Perhaps for [me and] many others, it's like the activity of other people in the community and their image can, in a certain way, create self-image pressures. ...nowadays it's of course very common in [SNS] that everyone maintains an image there and everyone reflects their self to [the SNS]."

Identity problems also included the burden of forfeiting one's own identity and private information. According to the interviewees, SNS jeopardise identity-related information, since such information can be sold to a third party, stolen, or otherwise taken advantage of. For example, one of the interviewees mentioned that his spouse's identity had been stolen and used for purchasing expensive goods.

Another social strain was social relation problems, which refer to the harmful effects of SNS use on one's interactions with other people (chain of evidence: Table 6). Six interviewees explicitly mentioned such effects but also others implied about them. SNS derived negative changes in one's 
online relations. For instance, the interviewees mentioned how their perceptions had changed about some of their peers after they had posted provocative content. Further, discussions and debates over such content can have a polarising effect, since they tend to drive people to opposite corners.

According to the data, SNS use can also harm one's social relations in the physical world, since it can make one's social life passive by creating the feeling of being constantly in touch with others. SNS use is, however, missing some dimensions of genuine face-to-face interaction. Thus, the interviewees stated that socialising in SNS "is not the same" and it "does not replace a human contact" in the physical world. For instance, one of the interviewees noticed how his close relations had suffered because of SNS use:

"[After using a particular SNS intensively for some time], I noticed how I didn't have enough time for my close ones and my circle of acquaintances. And how I was spending my time on my computer by checking what is up with my old classmates [on the SNS]. I was like, why am I using my time for this? If I quit [the particular SNS] entirely, I could, for instance, call that friend or visit a friend. That [SNS use] brought me an illusion of a social presence."

\section{Pattern 2 Stressors: Life Comparison Discrepancy, Online Discussion Conflict, and Privacy and Security Uncontrollability}

According to our data, the social strains can be traced back to three SNS stressors: life comparison discrepancy, conflicts in SNS discussions, and privacy and security uncontrollability. By life comparison discrepancy, we refer to the SNS users' discomfort when comparing their own life to the lives of others visible via SNS. As one interviewee put it simply, it is about the negative and tiring aspect of "stalking how others are doing". The interviewees emphasised how easy it is to compare the constantly on-going SNS posts and updates of others to their own life. Life comparison was perceived to be dangerous because it can form an infinite loop: one can always find an SNS post that showcases how someone is doing something better than its reader. The following excerpt illustrates the effects of such comparison to one's identity:

"It's like when I hear my friends saying, 'T've just browsed the profiles [in a particular SNS] for two hours'. Like I recently discussed [with my friends] that people go and peek at the lives of some friends of their friends or their ex [girlfriends and boyfriends], eh... It causes me to start thinking too much about everything... It's probably like that I start to compare myself [and my life] to the others and that kind of stuff." 
Table 5. Example chain of evidence: Identity problems

\begin{tabular}{|c|c|c|c|}
\hline Interviewee & IT Characteristics & Stressors & Strains \\
\hline $\begin{array}{l}\text { Amy, Woman, } \\
26 \\
\text { - Student, part- } \\
\text { time project } \\
\text { assistant } \\
\text { - Has used a } \\
\text { particular SNS } \\
\text { since 2007 } \\
\text { - Uses the SNS } \\
\text { “on a daily } \\
\text { basis” } \\
\text { - Has applied } \\
\text { the SNS on } \\
\text { smartphones } \\
\text { and } \\
\text { computers } \\
\text { - Used to post } \\
\text { weekly } \\
\text { updates, but } \\
\text { has reduced } \\
\text { their } \\
\text { frequency }\end{array}$ & $\begin{array}{l}\text { "TThrough SNS status updates] } \\
\text { I can kind of see how people are } \\
\text { doing with their lives and also } \\
\text { the other way around [what do } \\
\text { they think about my life]... If I } \\
\text { pushed a 'like' for something, I } \\
\text { will think about who will be } \\
\text { able to see that I like this kind } \\
\text { of thing." (coded to Self- } \\
\text { disclosure features) } \\
\text { "It's true: I also filter the kind } \\
\text { of funniest and best things [to } \\
\text { be used in status updates] and } \\
\text { other people surely do the } \\
\text { same, too. [Question:] Does } \\
\text { such [filtering] give people the } \\
\text { impression that you are doing } \\
\text { good? [Answer:] Yes." (coded to } \\
\text { Information cue paucity) }\end{array}$ & $\begin{array}{l}\text { "So if everyone had many happy things } \\
\text { posted [in their status updates] and if I } \\
\text { wasn't doing that good in life, I noticed } \\
\text { that [the other's updates] disturbed my } \\
\text { self... And [at the time] when I was } \\
\text { studying abroad... I felt like uploading } \\
\text { pictures and showcasing that 'I'm here } \\
\text { in Italy'." (coded to Life comparison } \\
\text { discrepancy) } \\
\text { "If I disagreed about a topic and wanted } \\
\text { to comment on it -- like about politics, } \\
\text { religion, or equality -- I still don't want } \\
\text { to take part in that discussion what } \\
\text { would begin... It's not a good situation } \\
\text { to discuss under someone's status } \\
\text { update when people will fight about } \\
\text { something." (coded to Online } \\
\text { discussion conflict) } \\
\text { "Ive thought about how safe the } \\
\text { discussions [in SNS] are. I don't have } \\
\text { the courage to think about it further. } \\
\text { We've talked about all kinds of things } \\
\text { there... Everyone always frightens } \\
\text { about [the privacy]... [The SNS] owns } \\
\text { your pictures and all the things you've } \\
\text { shared." (coded to Privacy and } \\
\text { security uncontrollability) }\end{array}$ & $\begin{array}{l}\text { "[Question:] Does your use of [the } \\
\text { SNS] bring you any harms? Does } \\
\text { it disturb your life or everyday } \\
\text { routines? [Answer:] ...somewhere } \\
\text { down the line I noticed that [SNS } \\
\text { use] influences me, so that the } \\
\text { other users' status updates and } \\
\text { posts have an effect on my self... } \\
\text { And [vice versa] yes, if someone } \\
\text { sees [my profile and all of its } \\
\text { information] in the future, I } \\
\text { ponder what they think of it... If I } \\
\text { put a 'like' on something public, } \\
\text { the whole world can profile me, } \\
\text { that I like this kind of thing." } \\
\text { (coded to Identity problems) }\end{array}$ \\
\hline
\end{tabular}

Table 6. Example chain of evidence: Social relation problems

\begin{tabular}{|c|c|c|c|}
\hline Interviewee & IT Characteristics & Stressors & Strains \\
\hline $\begin{array}{l}\text { Geoff, Man, } 36 \\
\text { - Athlete } \\
\text { - Used a } \\
\text { particular } \\
\text { microblog } \\
\text { since } 2010 \\
\text { - Used to apply } \\
\text { the microblog } \\
\text { frequently } \\
\text { during the day } \\
\text { - Removed the } \\
\text { microblog } \\
\text { account in } \\
\text { 2011 after } \\
\text { perceiving } \\
\text { substantial } \\
\text { harms }\end{array}$ & $\begin{array}{l}\text { "Some of my earlier [updates] } \\
\text { were like flypaper: they caught } \\
\text { everyone's [negative } \\
\text { attention]... [My feelings] were } \\
\text { just gushing to the Internet [via } \\
\text { microblog updates and } \\
\text { messages]." (coded to Self- } \\
\text { disclosure features) } \\
\text { "The problem with [the } \\
\text { microblog] and other [SNS] is } \\
\text { the limited amount of [textual] } \\
\text { characters. ... with [the } \\
\text { microblog] - even with blogs } \\
\text { with a greater amount of } \\
\text { available characters - the } \\
\text { readers or listeners can never } \\
\text { understand those wordplays } \\
\text { and puns in the [SNS] posts. } \\
\text { They can always be wrongly } \\
\text { interpreted in so many ways. } \\
\text { And sometimes they are } \\
\text { purposefully wrongly } \\
\text { interpreted." (coded to } \\
\text { Information cue paucity) }\end{array}$ & $\begin{array}{l}\text { "I took a stand on [sensitive sports } \\
\text { funding and performance issues]... I } \\
\text { was arguing with sports journalists like } \\
\text { 'these reporters don't understand } \\
\text { anything, this is bullsh\#t'.. Those } \\
\text { debates got so much out of hand that } \\
\text { they became burdensome... The debates } \\
\text { did not end by debating. The ruckus just } \\
\text { grew." (coded to Online discussion } \\
\text { conflict) } \\
\text { "At some point I will apply for a } \\
\text { [regular] job. At some point the darn } \\
\text { employers will check what kinds of } \\
\text { opinions I have and what have I } \\
\text { discussed [previously on the Internet]. } \\
\text { They will check all the things. I'm } \\
\text { wondering like 'wait a minute, what } \\
\text { kind of impression will they get of me?"” } \\
\text { (coded to Privacy and security } \\
\text { uncontrollability) } \\
\text { "Nowadays using [another popular } \\
\text { SNS] would be even more poisonous for } \\
\text { me because it combines the downsides of } \\
\text { [the previous microblog]: the never- } \\
\text { ending altercation debates and stalking } \\
\text { of how other people are doing." (coded } \\
\text { to Life comparison discrepancy) }\end{array}$ & $\begin{array}{l}\text { "Initially it was nice to be online } \\
\text { and discuss, but it went overboard } \\
\text { and turned into negative... I've } \\
\text { noticed that when I take a stand } \\
\text { on [SNS debates about sensitive } \\
\text { sports topics], and I've received } \\
\text { some initial attention from [the } \\
\text { opposing side] or they have } \\
\text { assigned me with a certain } \\
\text { profile, I begin to attract even } \\
\text { more attention than before... First } \\
\text { I was defending myself, then my } \\
\text { sport, and finally my friends... For } \\
\text { example, I vented about [a sports } \\
\text { issue] rather harshly and it } \\
\text { resulted into a quite big feud } \\
\text { between [two sport institutions]. } \\
\text { It went to the newspapers and so } \\
\text { on." (coded to Social relation } \\
\text { problems) }\end{array}$ \\
\hline
\end{tabular}


Online discussion conflict refers to the public or private disputes between two or more users of SNS. The interviewees referred how they were displeased when they were driven into online arguments or witnessed other users' altercations. The subjects of the debates ranged from politics and religion to hobbies and leisure activities. Specifically, the interviewees worried how "intense", "nasty", and "personal" such conflicts can get. "They directly bash each other there", as one interviewee put it. Another interviewee described how a conflict within an SNS group of dog owners had evolved into a war that was even reported in a national newspaper:

“...I'm involved in a dog breed group [in a particular SNS]. And there's, I guess like every spring, some fight about whether that particular breed should be trimmed and cut the dog's fur to zero for summer [laughs]... So, an actual war breaks out. There was a really long discussion thread under one photo of a trimmed dog... People were like 'yuck how ugly it is' and 'the dog is ruined'. ...so that, eventually, [a national newspaper] ended up writing a story about that particular [SNS] fight."

Privacy and security uncontrollability reflect the user's possibilities to control how their personal information is shared via SNS (both within the visible SNS or behind the scenes). The interviewees perceived that sharing detailed private information could turn against them if their network members "knew too much about" them or their sensitive information ended up in the wrong hands. The more severely perceived security risks included surveillance, theft of bank account information, and other profile hacking. These aspects contributed to identity pressures, since many interviewees thought they had to keep sharing personal information to maintain their identities via SNS despite the uncontrollability. For example, one of the interviewees described how he had been balancing between identity building and his concerns related to privacy and security:

"[Previously] all of my status updates were public. My photos were public. I didn't pay attention to it at all. I just posted all kinds of personal stuff visible for everyone. All kinds of stuff that I still regret today... The media has influenced me by shouting, 'protect your privacy' and 'the [particular SNS] accesses all of your photos and such'... [But nowadays] I tend to delete my [recent] updates after a while, basically after people have seen them... Now I behave more reasonably so that I don't have to regret my older status updates or photos or others... Perhaps I don't need to think it over so much, like what would suchand-such people think about [my SNS posts and activities]."

\section{Pattern 2 SNS Characteristics: Self-disclosure Features and Information Cue Paucity}

Two SNS characteristics induced life comparison discrepancy, online discussion conflict, and privacy and security uncontrollability: self-disclosure features and information cue paucity. These characteristics are elaborated as follows.

First, self-disclosure features enable life comparison, online discussion, and privacy and security uncontrollability, since they allow users to reveal information about themselves. In SNS, self-disclosure occurs through personal profiles and posts such as status updates, discussion comments and messages, likes, photos, and videos. These profiles and posts reflect various life 
activities and create an image about the person posting them. Therefore, users can compare such images with their self-image. The profiles and posts also open up the possibilities for online discussion disputes, as well as personal information misuse. For example, one of the interviewees described how SNS play a key role in presenting one's life to be compared with others:

"I feel like [a particular SNS] is kind of an extension of one's self image. [The SNS] is used to maintain and build that self image. ...I think [the SNS] is quite a blatant tool for highlighting oneself and one's merits. During these times, people should highlight themselves less and, kind of, just be. So that there would be no stress about what other people think about me and what kind of image I present to others about myself."

Information cue paucity refers to the lack of information richness: information delivered via SNS tends to be limited, one-sided, and open to multiple interpretations. The interviewees described how such paucity can enable users to shape the self image to be presented for others, make quick interpretations about other people's posts or miss some stylistic aspects of communication (e.g., sarcasm). This is particularly the case with short textual information (e.g., microblogs and status updates), but also with other media forms. For example, the interviewees described how SNS users are able to give "a polished view" by "selectively choosing [the most fitting] portions of one's life" to be portrayed to others via photo updates. Thus, the information cue paucity can lay the foundation for skewed life comparison dilemmas and discussion conflicts. In contrast to offline discussions, the interviewees highlighted how it can be inflammable to post opinions and participate in conversations online. For example, one interviewee described the limitedness of information as follows:

"The problem with [a particular SNS] and other [SNS] is the limited amount of [textual] characters: People rarely end up in trouble when discussing these issues face to face with friends or strangers. However, with [SNS] - even with blogs with a greater amount of available characters - the readers or listeners can never understand those wordplays and puns in the [SNS] posts. They can always be wrongly interpreted in so many ways. And sometimes they are purposefully wrongly interpreted."

In sum, Figure 4 illustrates the SNS characteristics and SNS stressors behind the social strains of SNS use. 

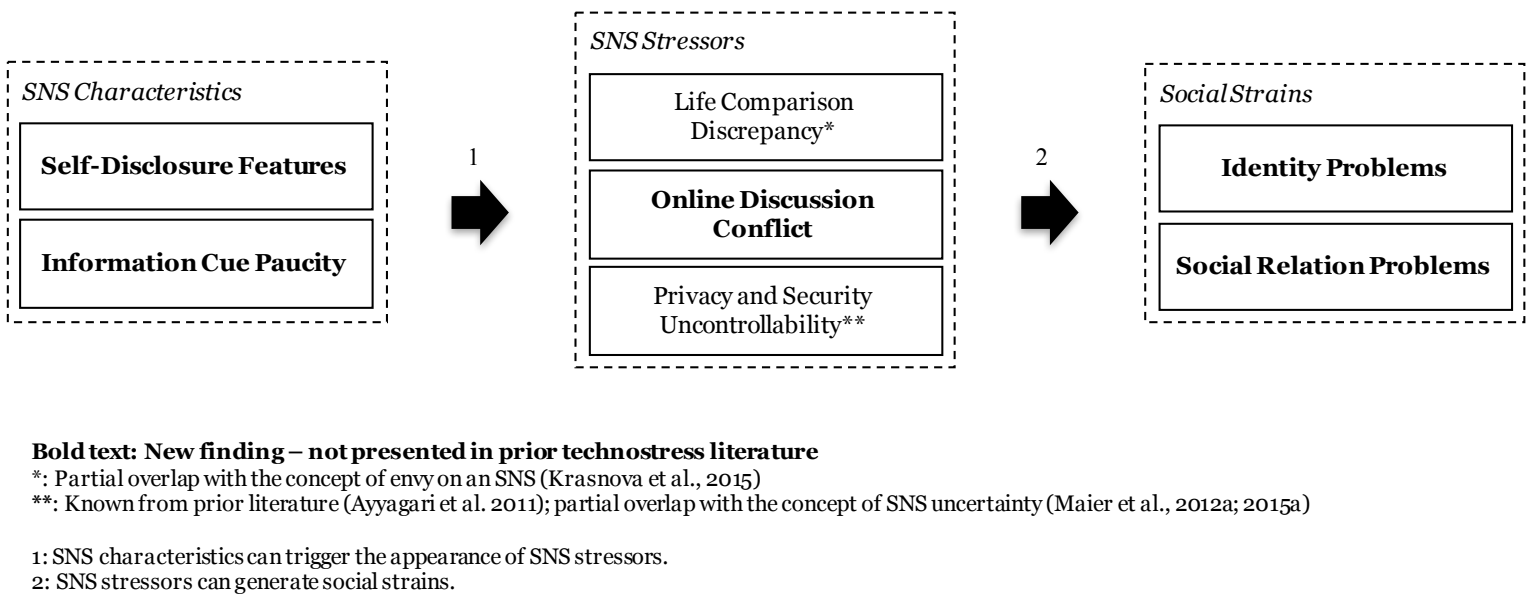

Figure 4. Pattern 2: SNS Characteristics and SNS Stressors Underlying Social Strains

\section{Discussion}

Despite the recent calls for research and a growing academic interest in technostress (e.g., Ayyagari et al., 2011; Ragu-Nathan et al., 2008; Tarafdar et al., 2007; 2011; 2015 Maier et al., 2015a; 2015b), there has been limited knowledge regarding the well-being strains related to SNS use. More specifically, the kinds of various well-being strains that SNS use can create and how these strains can be traced back to SNS stressors and SNS characteristics has been unknown up until now. An emphasis on well-being strains and the aspects behind them is important because understanding how actual problems are created can help individual users and their stakeholders to prevent the problems, engage in stress-free SNS use, and improve well-being (Brod, 1982; 1984; Krasnova et al., 2015; Lazarus, 1993). To address the research gap, this study contributes by identifying perceived well-being strains of the SNS stressors and uncovering their underlying SNS characteristics. As such, this study captured two primary patterns for strains (but does not rule out the possibility of some potential secondary interaction between the patterns). We illustrate the theoretical and practical implications that arise from this study as follows.

\section{Research Contributions}

First, this study contributes to the literature by introducing novel insights into SNS stress: the four well-being strains that are tied to the SNS stressors, the influence of the stressor-triggering SNS characteristics, and the two distinct patterns. While the prior literature concerning SNS stress has identified various SNS stressors and their subsequent use consequences (Brooks et al., 2017; Laumer et al., 2013; Maier et al., 2012a; 2012b; 2015a; 2015b), this study extends the prior understanding by focusing on the well-being strains and the SNS features. For instance, prior studies have provided valuable insights into how SNS stressors such as SNS invasion can lead to discontinued use (Maier et al., 2012a; 2015a). As such, they have valuably integrated SNS stressors with the usage dimension (i.e., discontinuous use of IT) by demonstrating how the stressors can convert users into ex-users (Maier et al., 2015a). To extend this knowledge, our study links SNS 
stressors with the well-being dimension by exploring how the certain SNS features trigger the stressors, which subsequently generate maladaptive strains related to the users' well-being. More specifically, we could not identify any empirical technostress studies that would account for concentration, sleep, identity, and social relation problems or SNS technology and information characteristics other than message notifications. This new set of findings therefore increases our understanding of how the various forms of technostress are derived from SNS use. Our findings suggest that individual strains link with the underlying SNS characteristics and stressors that differ from those pertaining to social strains. As such, we aim to offer a solution to a key problem that has been identified, namely that "the mechanisms behind the unfavorable consequences [of SNS use] remain unclear" (Krasnova et al., 2015, 586). Hence, we propose the following:

P1. Individual strains are linked with different sets of SNS stressors and SNS characteristics than those pertaining to social strains.

Based on our analysis, the abundance of arriving push notifications, the multipurpose features, and the constantly renewing information feeds associated with SNS expose users to the risk of becoming overly dependent on and overloaded by their SNS. These stressors can subsequently swallow users' attention and time (away from other activities) and contribute to concentration and sleep problems. Thus, we propose:

P2. Push notification features, multipurpose functionality, and real-time information renewability expose users to SNS overdependence and overload stressors, which can lead to concentration and sleep problems.

Correspondingly, features for disclosing personal information and the lack of information richness are the fundamentals of life comparison discrepancies, discussion conflicts, and privacy/security uncontrollability. These stressors shape users' self-reflections and interactions with others and can lead to identity and social relation problems. Therefore, we propose:

P3. Self-disclosure features and information cue paucity expose users to life comparison discrepancy, online discussion conflict, and privacy/security uncontrollability stressors, which can lead to identity and social relation problems.

P2 concerns individual strains, while P3 concerns social strains. The individual strains refer to users' responses and outcomes that are considered maladaptive for primarily private, independent perceptions and activities, while the social strains refer to users' responses and outcomes that are considered maladaptive for their public, interpersonal perceptions and activities (Butler \& Gross, 2009; Cooper et al., 2001; Tarafdar et al., 2015). Thus, the main difference between them is that the individual strains are primarily driven by self-contained perceptions and activities, while the social strains focus on perceptions and activities that are inextricable from others. A distinction between the individual and the social level is deemed important, since it can help researchers to understand where the problems are rooted (e.g., in different stressors and SNS characteristics) (Ayyagari et al., 2011). However, this distinction does not exclude potential interrelations between the two types of strains. 
Second, our findings uncovered new SNS-specific insights into the well-being strains and SNS characteristics. In contrast to the prior studies' focus on strains related to SNS use consequences (e.g., use discontinuance; Laumer et al., 2013; Luqman et al., 2017; Maier et al., 2012a; 2012b; 2015a; 2015b), our findings extend the current understanding by recognising the negative wellbeing outcomes of SNS use that "spill over" one degree further from the mere SNS use dimension. Thus, our findings contribute to the requests for identifying the adverse side-effects of IT use (Lee, 2015; 2016; Rai, 2016) by revealing users' perceived well-being strains as undesired effects that not only reflect SNS use but also disrupt other daily activities. Further, we extended prior knowledge by uncovering that the stressors and related strains derive from the characteristics typical for SNS such as multipurpose functionality, self-disclosure features, and information cue paucity. These findings extend the prior research concerning SNS stressors (Brooks et al., 2017; Laumer et al., 2013; Maier et al., 2012a; 2012b; 2015a; 2015b) by pinpointing the origins of those stressors. We further argue that the five SNS characteristics are related to most SNS but may manifest in different ways with different SNS. For example, self-disclosure features focus on visual expression with photo sharing applications, written expression with text-based messengers, and contextual expression with location based services. All of these manifestations of self-disclosure features can trigger life comparison discrepancies, for instance, by demonstrating beauty and richness via photos, prestigious life lessons via text, or travels via paradise resort locations. Similarly, information cue paucity can trigger discrepancies by textual limitedness in discussions and instant messaging (e.g., overemphasising success in life) or visual one-sidedness in photo sharing SNS (e.g., faking luxury life). While there are studies itemising SNS features and functionalities (e.g., Boyd \& Ellison, 2010; Richter \& Koch, 2008; Zhang \& Leung, 2015), they have not linked the features with technostress. Their presentation of the main SNS features resonate particularly with three characteristics of our study: notifications are named similarly; updates, comments, and likes reflect self-disclosure features; and feeds, walls, and timelines reflect real-time information renewability. This study integrates SNS characteristics with stress and, thus, includes a suggested emphasis on the IT artifact (Orlikowski \& Iacono, 2001; Sarker et al., 2013) that is deemed particularly important in the technostress research due to its ability to trace the root causes for users' stress experiences (Ayyagari et al., 2011).

Third, in addition to the "intradisciplinary contribution" of uncovering previously unknown wellbeing strains of SNS use and SNS characteristics, this study aims at an "interdisciplinary contribution" as recently encouraged and desired by several IS researchers (e.g., Grover \& Lyytinen, 2015; Tarafdar \& Davison, 2017). Especially technostress is an area of such potential "discourse of disciplinary exchange" (Tarafdar et al., 2017, 3). For example, there have been studies of some related aspects fragmented across different disciplines, such as self-promotional and antisocial SNS behaviour in psychology (Carpenter, 2012) and children's screen time and sleep in medicine (Hale \& Guan, 2015). However, most studies in other disciplines have treated IT as "taken for granted" (Orlikowski \& Iacono, 2001, 121) and examined it without opening the black box of IT use. Thus, they have not revealed a comprehensive picture about the IT characteristics underlying the behavioural problems. Indeed, we believe that other disciplines could take 
advantage of the knowledge created in IS to open the black box of IT and advance their understanding of the IT characteristics. The findings of our study could help, for example, psychologists and medical researchers to complement their research to identify, which characteristics of SNS create the behavioural outcomes they are focusing on.

Finally, the IT artifact and the term "information technology" also includes the information part, but there has been a lack of research on information characteristics related to technostress. Our study, however, suggests that information characteristics (namely, real-time information renewability and information cue paucity) also contribute to stressors and strains. For example, we determined that information cue paucity can contribute to strains since SNS information tends to be limited, one-sided, and open to multiple interpretations. Such information aspects have been acknowledged with other IS topics, such as media richness (e.g., Dennis et al., 2008) and studies focusing on the specific context of information overload (e.g., Weinert et al., 2012), but not in the technostress research. Thus, our findings also add to the extant view on technostress by suggesting that information characteristics must be taken into account when studying the determinants of stress related to IT use. This may open up possibilities for researchers to examine the links between information characteristics and technostress.

\section{Implications for Practice}

First, by identifying different kinds of strains and their primary determinants, it is now possible to help users and their stakeholders (e.g., families, friends, and health organisations) to acknowledge their strains, understand how they emerge, and increase their possibilities to avoid their strains in the future. This generates opportunities for designing and implementing tailored interventions for technostress reduction. For example, a user suffering from individual strains would benefit from decreasing their SNS overdependence and overload by muting push notifications and controlling cravings for new information. This could be attained, for example, by better monitoring the amount of one's incoming push notification and logins for new information. Indeed, thorough monitoring is important for acquiring a realistic picture of one's behaviour and changing unfavourable routines (Baumeister \& Vohs, 2007). In contrast, an individual suffering from social strains could benefit from putting life comparison and online discussions into perspective by acknowledging the limitedness of information posted in SNS. This could be reached by learning that SNS users often post a polished view about their lives and some online discussants purposely aim to provoke others. Thus, the actions tackling individual strains indicate a need to improve pragmatic self-control in the daily habits and practices of using SNS, while the actions aimed at social strains appear to necessitate a calmer attitude towards SNS use.

Second, it is currently common for employees to use their personal SNS during their working time (Lim \& Chen, 2012). Thus, well-being strains deriving from personal/leisure use can also affect the users' performance at work, for example, via concentration problems. Thus, organisations as employers have to be aware of such effects. Organisations could attempt to decrease their employees' strains by educating them about the negative side effects of SNS use. A particularly powerful approach could be one that highlights the concrete side-effects from the employee's 
perspective: In the end, employees are assumedly the ones who will face the most harm from their strains.

Finally, it could be a long-term benefit for SNS providers and developers to support their users' efforts to remain free of stress, since SNS stress has been linked with discontinued use (Laumer et al., 2013; Luqman et al., 2017; Maier et al., 2012a; 2012b; 2015a; 2015b). Our findings can make it possible to form early estimations of how different SNS characteristics can create stress and use that knowledge when designing SNS and other IT with social features and elements. Assumedly, this consideration will be highlighted more and more in the future because social features and elements are becoming essential parts of nearly all kinds of IT designed for both personal/leisure and organisational use contexts. For instance, the providers and developers could pay specific attention to the default settings that the users are offered when they start to use SNS from scratch. Although it can be tempting to try to engage the newly acquired users in SNS use as much as possible, it may be questionable to set overwhelming default settings, such as assigning automatic push notifications from every single SNS activity. Users may find some of the push notifications to be redundant and disturbing, which could eventually lead to fewer occasions of SNS use or cessation. Within our data set, nearly all interviewees stated how they had perceived a need to reduce the amount of push notifications in the initial stages of their SNS use. Therefore, the default settings that many SNS providers use are, perhaps, not optimal.

\section{Limitations and Future Topics}

There are certain limitations regarding this study. First, this research aimed to capture and distinguish the SNS characteristics and stressors for both main types of strains (individual and social), although the strains, stressors, and SNS characteristics may not be completely exclusive and some secondary interaction between them may occur. In particular, it appears that the individual strains can subsequently contribute to social strains and vice versa. For instance, SNS users' concentration problems can distract their focus during social interactions and potentially affect their social relationships. Similarly, users' identity problems derived from SNS can possibly keep them up at night and hinder sleep. We encourage researchers to investigate such potential interactions in the future. Second, prior studies have suggested potential SNS stressors that did not appear essential for the strains related to well-being that were examined in this study. For instance, the SNS complexity stressor (Maier et al., 2012a; 2015a) could prove more influential with strains related to SNS use consequences (e.g., dissatisfaction and discontinuance) than with strains related to well-being. Third, we collected self-reported, rather than physiological, data about users' perceptions. However, such self-reported and perception-based data have been found reliable for studying technostress (Ayyagari et al., 2011; Ragu-Nathan et al., 2008). Fourth, our study focused on the users' subjective experience of stress and did not capture any potential effects of IT on a biological level (e.g., chemicals or radiofrequency radiation). For instance, with concentration and sleep problems we examined the perceived behavioural effects of SNS use (e.g., reading session or sleep concretely disrupted by overload from notifications). Fifth, SNS use may be only one contributor to users' concentration, sleep, identity, and social relation problems, which may result from a combined effect of several factors. Sixth, since data collection with retrospective approaches 
such as narratives may relate to recall and re-interpretation issues (Folkman \& Moskowitz, 2004), we aimed to anchor questions, responses, and examples in real-life events and instructed the interviewees to think carefully about their past experiences. Seventh, our interviewees were Finnish and, hence, some of the findings may relate to nationality and culture. Finally, in line with prior studies, we focused on the negative side of technostress, although stress can, in some circumstances, also be linked to some positive aspects (Califf et al., 2015).

The results of this study suggest areas that researchers could examine in the future. First, our study revealed various well-being strains, but did not focus on examining whether the problems are temporary or enduring. Thus, researchers could utilise longitudinal approaches to study how permanent and frequent these problems are. Second, this study focused on SNS in the personal/leisure use context. Since SNS features are presently becoming increasingly popular with work IT, strains of work-related SNS could be studied in organisational contexts. Finally, we encourage researchers to pay attention to the ways in which the strains could be reduced. The findings of this study could be utilised to examine different ways to reduce the strains: some for individual strains and others for social strains.

\section{Conclusions}

The increasingly popular use of SNS has been associated with adverse side-effects such as technostress. According to recent practitioner reports, users can suffer from various well-being strains due to SNS use. While prior studies concerning SNS stress have provided valuable knowledge regarding SNS stressors, they have not examined the associated strains related to wellbeing nor the stressor-creating SNS characteristics. Therefore, we aimed to explore this area of research. Our study revealed that SNS use can contribute to concentration, sleep, identity, and social relation problems. We found two distinct patterns behind the strains. Our findings thus contribute to the calls for uncovering the adverse side-effects of IT use and the mechanisms behind them. More specifically, the findings extend prior knowledge by presenting sets of SNS characteristics for the SNS stressors and identifying well-being strains beyond the SNS use consequences (e.g., discontinuance). Additionally, researchers in other disciplines can potentially take advantage of our findings and open the black box of SNS use by applying the stressor-creating SNS characteristics.

\section{Acknowledgements}

We thank Mika Kovanen and Seppo Risku for their assistance and insights. We would also like to thank the senior editor, the associate editor, and the two anonymous reviewers for their excellent and helpful advices.

\section{References}

Ahmad, U.N.U., Amin, S.M. \& Ismail, W.K.W. (2012). The relationship between technostress creators and organisational commitment among academic librarians. Procedia-Social and 
Behavioral Sciences, 40, 182-186.

AIS. (2011). Association for Information Systems: Senior scholars' basket of journals. Retrieved $16^{\text {th }}$ January 2018. http://aisnet.org/?SeniorScholarBasket

Arnetz, B.B. (1996). Techno-stress: A perspective psychophysiological study of the impact of a controlled stress-reduction program in advanced telecommunications systems design work. Journal of Occupational \& Environmental Medicine, 38(1), 53-65.

Ayyagari, R., Grover, V. \& Purvis, R. (2011). Technostress: Technological antecedents and implications. MIS Quarterly, 35(4), 831-858.

Baumeister, R.F., \& Vohs, K.D. (2007). Self-Regulation, ego depletion, and motivation. Social and Personality Psychology Compass, 1(1), 115-128.

Barley, S.R., Meyerson, D.E. \& Grodal, S. (2011). E-mail as a source and symbol of stress. Organization Science, 22(4), 887-906.

Berg, B.L. (2004). Qualitative research methods for the social sciences. Boston, MA: Pearson Education.

Bichteler, J. (1987). Technostress in libraries: Causes, effects and solutions. The Electronic Library, $5(5), 282-287$.

Boyd, D. \& Ellison, N.B. (2007). Social network sites: Definition, history, and scholarship. Journal of Computer-Mediated Communication, 13(1), 210-230.

Brod, C. (1982). Managing technostress: Optimizing the use of computer technology. Personnel Journal, 61, 753-57.

Brod, C. (1984). Technostress: The human cost of the computer revolution. Addison Wesley Publishing Company.

Brooks, S., Longstreet, P. \& Califf, C. (2017). Social media induced technostress and its impact on Internet addiction: A distraction-conflict theory perspective. AIS Transactions on HumanComputer Interaction, 9(2), 99-122.

Butler, E.A. \& Gross, J.J. (2009). Emotion and emotion regulation: Integrating individual and social levels of analysis. Emotion Review, 1(1), 86-87.

Califf, C., Sarker, S., Sarker, S. \& Fitzgerald, C. (2015). The bright and dark sides of technostress: An empirical study of healthcare workers. In: Proceedings of the International Conference on Information Systems (ICIS).

Carpenter, C.J. (2012). Narcissism on Facebook: Self-promotional and anti-social behavior. Personality and individual differences, 52(4), 482-486.

Carter, M. \& Grover, V. (2015). Me, myself, and I(T): Conceptualizing information technology identity and its implications. MIS Quarterly, 39(4), 931-957.

CNBC. (2017). Facebook's Instagram Stories crushes Snapchat with 250 million daily active users. 
Retrieved 21st June 2017. http://www.cnbc.com/2017/06/20/instagram-crushes-snapchatsdaily-active-users-rate.html

Cooper, C.L., Dewe, P.J. \& O'Driscoll, M.P. (2001). Organizational stress: A review and critique of theory, research, and applications. Thousand Oaks, CA: Sage Publications.

D’Arcy, J., Herath, T. \& Shoss, M. (2014). Understanding employee responses to stressful information security requirements: A coping perspective. Journal of Management Information Systems, 31(2), 285-318.

Dennis, A.R., Fuller, R.M. \& Valacich, J. S. (2008). Media, tasks, and communication processes: A theory of media synchronicity. MIS Quarterly, 32(3), 575-600.

Dscout. (2016). Mobile Touches report. Retrieved $3^{\text {rd }}$ November 2017.

https://blog.dscout.com/hubfs/downloads/dscout_mobile_touches_study_2016.pdf

Edwards, J.R. \& Cooper, C.L. (1988). Research in stress, coping and health: Theoretical and methodological issues. Psychological Medicine, 18, 331-350.

Edwards, J.R. \& Cooper, C.L. (1990). The person-environment fit approach to stress: Recurring problems and some suggested solutions. Journal of Organizational Behavior, 10, 293-307.

Fischer, T. \& Riedl, R. (2017). Technostress research: A nurturing ground for measurement pluralism? Communications of the Association for Information Systems, 40, 375-401.

Folkman, S. (1999). Foreword. In R.S. Lazarus (Ed.), Stress and Emotion: A New Synthesis. New York: Springer.

Folkman, S. \& Moskowitz, J.T. (2004). Coping: Pitfalls and promise. Annual Review of Psychology, 55, 745-774.

Fuglseth, A.M. \& Sørebø, Ø. (2014). The effects of technostress within the context of employee use of ICT. Computers in Human Behavior, 40, 161-170.

Galluch, P., Grover, V. \& Thatcher, J. (2015). Interrupting the workplace: Examining stressors in an information technology context. Journal of the Association for Information Systems, 16(1), 147.

George, J.F. (1996). Computer-based monitoring: Common perceptions and empirical results. MIS Quarterly, 20(4), 459-480.

Greubel, J. \& Kecklund, G. (2011). The impact of organizational changes on work stress, sleep, recovery and health. Industrial Health, 49(3), 353-364.

Grover, V. \& Lyytinen, K. (2015). New state of play in information systems research: The push to the edges. MIS Quarterly, 39(2), 271-296.

Gruen, D., Rauch, T., Redpath, S. \& Ruettinger, S. (2002). The use of stories in user experience design. International Journal of Human-Computer Interaction, 14(3-4), 503-534.

Hale, L. \& Guan, S. (2015). Screen time and sleep among school-aged children and adolescents: A 
systematic literature review. Sleep medicine reviews, 21, 50-58.

Hsiao, K.L., Shu, Y. \& Huang, T.C. (2017). Exploring the effect of compulsive social app usage on technostress and academic performance: Perspectives from personality traits. Telematics and Informatics, 34(2), 679-690.

Hudiburg, R.A. (1989). Psychology of computer use: VII. Measuring technostress: Computerrelated stress. Psychological Reports, 64(3), 767-772.

Huffington Post. (2013). Why do social networks increase stress? Retrieved $24^{\text {th }}$ February 2017. http://www.huffingtonpost.com/john-dick/social-networks-and-stress_b_353417o.html

Hung, W.H., Chang, L.M. \& Lin, C.H. (2011). Managing the risk of overusing mobile phones in the working environment: A study of ubiquitous technostress. In: Proceedings of the Pacific Asia Conference on Information Systems (PACIS).

Hung, W.H., Chen, K. \& Lin, C.P. (2015). Does the proactive personality mitigate the adverse effect of technostress on productivity in the mobile environment? Telematics and Informatics, 32(1), $143-157$.

Kim, H.W., Chan, H.C. \& Chan, Y.P. (2007). A balanced thinking-feelings model of information systems continuance. International Journal of Human-Computer Studies, 65(6), 511-525.

Klein, H.K. \& Myers, M.D. (1999). A set of principles for conducting and evaluating interpretive field studies in information systems. MIS Quarterly, 23(1), 67-93.

Koch, H., Gonzalez, E. \& Leidner, D. (2012). Bridging the Work/Social Divide: The Emotional Response to Organizational Social Networking Sites. European Journal of Information Systems, 21(6), 699-717.

Krasnova, H., Widjaja, T., Buxmann, P., Wenninger, H. \& Benbasat, I. (2015). Why following friends can hurt you: An exploratory investigation of the effects of envy on social networking sites among college-age users. Information Systems Research, 26(3), 585-605.

Kupersmith, J. (1992). Technostress and the reference librarian. Reference Services Review, 20(2), 7-50.

Laumer, S., Maier, C. \& Weinert, C. (2013). The negative side of ICT-enabled communication: The case of social interaction overload in online social networks. In: Proceedings of the European Conference on Information Systems (ECIS).

Lazarus, R.S. (1966). Psychological stress and the coping process. New York: McGraw-Hill.

Lazarus, R.S. (1993). Coping theory and research: Past, present, and future. Psychosomatic Medicine, 55(3), 234-247.

Lazarus, R.S. \& Folkman S. (1984). Stress, appraisal, and coping. New York: Springer Publishing Company.

Lee, J.K. (2015). Guest Editorial: Research framework for AIS grand vision of the bright ICT 
initiative. MIS Quarterly, 39(2), iii-xii.

Lee, J.K. (2016). Invited Commentary: Reflections on ICT-enabled bright society research. Information Systems Research, 27(1), 1-5.

Lee, Y.K., Chang, C.T., Lin, Y. \& Cheng, Z.H. (2014). The dark side of smartphone usage: Psychological traits, compulsive behavior and technostress. Computers in Human Behavior, 31, $373-383$.

Leung, L. \& Zhang, R. (2017). Mapping ICT use at home and telecommuting practices: A perspective from work/family border theory. Telematics and Informatics, 34(1), 385-396.

Lim, V.K. \& Chen, D.J. (2012). Cyberloafing at the workplace: Gain or drain on work? Behaviour \& Information Technology, 31(4), 343-353.

Lin, K.Y. \& Lu, H.P. (2011). Why people use social networking sites: An empirical study integrating network externalities and motivation theory. Computers in Human Behavior, 27(3), 1152-1161.

Luqman, A., Cao, X., Ali, A., Masood, A. \& Yu, L. (2017). Empirical investigation of Facebook discontinues usage intentions based on SOR paradigm. Computers in Human Behavior, available online.

Maier, C., Laumer, S., Eckhardt, A. \& Weitzel, T. (2012a). Online social networks as a source and symbol of stress: an empirical analysis. In: Proceedings of the International Conference on Information Systems (ICIS).

Maier, C., Laumer, S., Eckhardt, A. \& Weitzel, T. (2012b). When social networking turns to social overload: Explaining the stress, emotional exhaustion, and quitting behavior from social network sites' users. In: Proceedings of the European Conference on Information Systems (ECIS).

Maier, C., Laumer, S., Eckhardt, A. \& Weitzel, T. (2015a). Giving too much social support: Social overload on social networking sites. European Journal of Information Systems, 24(5), 447464 .

Maier, C., Laumer, S., Weinert, C. \& Weitzel, T. (2015b). The effects of technostress and switching stress on discontinued use of social networking services: A study of Facebook use. Information Systems Journal, 25(3), 275-308.

Maier, C., Laumer, S. \& Eckhardt, A. (2015c). Information technology as daily stressor: pinning down the causes of burnout. Journal of Business Economics, 85(4), 349-387.

Miles, M.B. \& Huberman, A.M. 1994. Qualitative data analysis: A sourcebook. Beverly Hills: Sage Publications.

Moody, G.D. \& Galletta, D.F. (2015). Lost in cyberspace: The impact of information scent and time constraints on stress, performance, and attitudes online. Journal of Management Information Systems, 32(1), 192-224.

Myers, M.D. (1997). Qualitative research in information systems. MIS Quarterly, 21(2), 241-242. 
Myers, M.D. \& Newman, M. (2007). The qualitative interview in IS research: Examining the craft. Information and Organization, 17(1), 2-26.

New York Post. (2017). Why Facebook feeds division and stress. Retrieved $24^{\text {th }}$ February 2017. http://nypost.com/2017/02/18/why-facebook-feeds-division-and-stress/

Orlikowski, W.J. \& Iacono, C.S. (2001). Research Commentary: Desperately seeking the "IT" in IT research: A call to theorizing the IT artifact. Information Systems Research, 12(2), 121-134.

Patton, M.Q. (1990). Qualitative evaluation and research methods. SAGE Publications, inc.

Pawlowski, S.D., Kaganer, E.A. \& Cater, J.J. (2007). Focusing the research agenda on burnout in IT: Social representations of burnout in the profession. European Journal of Information Systems, 16(5), 612-627.

PBS Newshour. (2015). This is how Facebook stresses you out, according to study. Retrieved $24^{\text {th }}$ February 2017. http://www.pbs.org/newshour/rundown/social-media-stress-contagious/

Pentland, B.T (1999). Building process theory with narrative: From description to explanation. Academy of Management Review, 24(4), 711-724.

Pew Research Center. (2016). The Political Environment on Social Media. Retrieved $3^{\text {rd }}$ November 2017. http://www.pewinternet.org/2016/10/25/the-political-environment-on-social-media/

Pirkkalainen, H. \& Salo, M. (2016). Two decades of the dark side in the information systems basket: Suggesting five areas for future research. In: Proceedings of the European Conference on Information Systems (ECIS).

Ragu-Nathan, T.S., Tarafdar, M., Ragu-Nathan, B.S. \& Tu, Q. (2008). The consequences of technostress for end users in organizations: Conceptual development and validation. Information Systems Research, 19(4), 417-433.

Rai, A. (2016). Editor's Comments: The MIS Quarterly trifecta: Impact, range, speed. MIS Quarterly, 40(1), iii-x.

Richter, A. \& Koch, M. (2008). Functions of social networking services. In: Proceedings of the International Conference on the Design of Cooperative Systems, 87-98.

Riedl, R., Kindermann, H., Auinger, A. \& Javor, A. (2012). Technostress from a neurobiological perspective. Business \& Information Systems Engineering, 4(2), 61-69.

Sadeh, A., Keinan, G. \& Daon, K. (2004). Effects of stress on sleep: the moderating role of coping style. Health Psychology, 23(5), 542-545.

Salanova, M., Llorens, S. \& Cifre, E. (2013). The dark side of technologies: Technostress among users of information and communication technologies. International Journal of Psychology, $48(3), 422-436$.

Sarker, S., Xiao, X. \& Beaulieu, T. (2013). Guest editorial: Qualitative studies in information systems: a critical review and some guiding principles. MIS Quarterly, 37(4), iii-xviii. 
Schwarz, A., Chin, W.W., Hirschheim, R. \& Schwarz, C. (2014). Toward a process-based view of information technology acceptance. Journal of Information Technology, 29(1), 73-96.

Shu, Q., Tu, Q. \& Wang, K. (2011). The impact of computer self-efficacy and technology dependence on computer-related technostress: A social cognitive theory perspective. International Journal of Human-Computer Interaction, 27(10), 923-939.

Srivastava, S.C., Chandra, S. \& Shirish, A. (2015). Technostress creators and job outcomes: Theorising the moderating influence of personality traits. Information Systems Journal, 25(4), $355^{-401 .}$

Tams, S., Hill, K., Ortiz de Guinea, A., Thatcher, J. \& Grover, V. (2014). Alternative or complement to existing methods? Illustrating the holistic effects of neuroscience and self-reported data in the context of technostress research. Journal of the Association for Information Systems, 15(10), 723-753.

Tarafdar, M., Bolman, E., Pullins, E.B. \& Ragu-Nathan, T.S. (2015). Technostress: Negative effect on performance and possible mitigations. Information Systems Journal, 25(2), 103-132.

Tarafdar, M., Cooper, C.L. \& Stich, J.F. (2017). The technostress trifecta-techno eustress, techno distress and design: Theoretical directions and an agenda for research. Information Systems Journal, available online.

Tarafdar, M. \& Davison, R. (2017). Research in Information Systems: Intra-disciplinary and Interdisciplinary Approaches. Journal of the Association for Information Systems, available online.

Tarafdar, M., Tu, Q., Ragu-Nathan, B. \& Ragu-Nathan, T.S. (2007). The impact of technostress on role stress and productivity. Journal of Management Information Systems, 24(1), 301-328.

Tarafdar, M., Tu, Q. \& Ragu-Nathan, T.S. (2011). Impact of technostress on end-user satisfaction and performance. Journal of Management Information Systems, 27(3), 303-334.

The Guardian. (2017). "Our minds can be hijacked": The tech insiders who fear a smartphone dystopia. Retrieved $3^{\text {rd }}$ November 2017.

https://www.theguardian.com/technology/2017/oct/o5/smartphone-addiction-silicon-valleydystopia

The Happiness Research Institute. (2015). The Facebook experiment: Does social media affect the quality of our lives? Retrieved $3^{\text {rd }}$ November 2017.

https://docs.wixstatic.com/ugd/928487_68ofc12644c8428eb728cde7d61b13e7.pdf

Thoits, P.A. (2013). Self, identity, stress, and mental health. In: Handbook of the Sociology of Mental Health (357-377). Springer Netherlands.

Tu, Q., Wang, K. \& Shu, Q. (2005). Computer-related technostress in China. Communications of the ACM, 48(4), 77-81.

van der Heijden, H. (2012). User acceptance of electronic commerce: Contributions from the Bled eConference. BLED 2012, Special Issue. 
Venkatesh, V., Brown, S.A. \& Bala, H. (2013). Bridging the qualitative-quantitative divide: Guidelines for conducting mixed methods research in information systems. MIS Quarterly, $37(1), 21-54$.

Venkatesh, V., Thong, J.Y.L. \& Xu, X. (2012). Consumer acceptance and use of information technology: Extending the unified theory of acceptance and use of technology. MIS Quarterly, 36(1), 157-178.

Wang, K., Shu, Q. \& Tu, Q. (2008). Technostress under different organizational environments: An empirical investigation. Computers in Human Behavior, 24(6), 3002-3013.

Webster, J. \& Watson, R.T. (2002). Analyzing the past to prepare for the future: Writing a literature review. MIS Quarterly, 26(2), xiii-xxiii.

Weinert, C., Laumer, S. \& Maier, C. (2012). The shady side of Facebook: The influence of perceived information and network characteristics on the attitude towards information overload. In: Proceedings of the Americas Conference on Information Systems (AMCIS).

Wu, J. \& Lu, X. (2013). Effects of extrinsic and intrinsic motivators on using utilitarian, hedonic, and dual-purposed information systems: A meta-analysis. Journal of the Association for Information Systems, 14(3), 153-191.

Zhang, Y. \& Leung, L. (2015). A review of social networking service (SNS) research in communication journals from 2006 to 2011. New Media \& Society, 17(7), 1007-1024. 


\section{Appendix. Prior technostress studies focusing on contexts other than SNS}

\begin{tabular}{|c|c|c|c|c|}
\hline Article & Context & IT Characteristics & Stressors & Strains \\
\hline Ahmad et al. 2012 & Organisational & - & IT stressors & Reduced commitment \\
\hline Arnetz 1996 & Organisational & - & - & Mental strain \\
\hline Ayyagari et al. 2011 & Organisational & $\begin{array}{l}\text { Work IT } \\
\text { characteristics }\end{array}$ & IT / task & Strain \\
\hline Barley et al. 2011 & Organisational & - & IT / task & Stress \\
\hline Bichteler 1987 & Organisational & $\begin{array}{l}\text { Database and } \\
\text { catalogue functions, } \\
\text { bugs }\end{array}$ & IT / task & $\begin{array}{l}\text { Technostress, resistance- } \\
\text { behaviour }\end{array}$ \\
\hline Brod 1982 & Organisational & - & IT / task & IT resistance \\
\hline D'arcy et al. 2014 & Organisational & - & Security policy & ISP-violating behaviour \\
\hline $\begin{array}{l}\text { Fuglseth \& Sørebø } \\
2014\end{array}$ & Organisational & - & IT stressors & Reduced satisfaction \\
\hline Galluch et al. 2015 & Organisational & Interruptions & - & Strain \\
\hline George 1996 & Organisational & - & Monitoring & Stress \\
\hline Koch et al. 2012 & Organisational & $\begin{array}{l}\text { (System features } \\
\text { described but not } \\
\text { linked to stressors) }\end{array}$ & $\begin{array}{l}\text { Use of work- } \\
\text { related SNS }\end{array}$ & Stress \\
\hline Kupersmith 1992 & Organisational & Database functions & IT use & Technostress \\
\hline Maier et al. 2015c & Organisational & - & IT / task & Exhaustion \\
\hline Pawlowski et al. 2007 & Organisational & - & IT / task & Reduced performance \\
\hline $\begin{array}{l}\text { Ragu-Nathan et al. } \\
2008\end{array}$ & Organisational & - & IT stressors & Reduced commitment \\
\hline Riedl et al. 2012 & Organisational & System breakdown & IT & Technostress \\
\hline Salanova et al. 2013 & Organisational & - & Job demands & Strain, addiction \\
\hline Shu et al. 2011 & Organisational & - & IT dependence & Technostress \\
\hline Srivastava et al. 2015 & Organisational & - & IT stressors & Job burnout \\
\hline Tarafdar et al. 2007 & Organisational & - & IT stressors & Reduced productivity \\
\hline Tarafdar et al. 2011 & Organisational & - & IT stressors & Reduced satisfaction \\
\hline Tarafdar et al. 2015 & Organisational & - & IT stressors & $\begin{array}{l}\text { Reduced IT/work } \\
\text { performance/innovation }\end{array}$ \\
\hline Tu et al. 2005 & Organisational & - & IT stressors & Reduced productivity \\
\hline Wang et al. 2008 & Organisational & - & $\begin{array}{l}\text { Organizational } \\
\text { factors }\end{array}$ & Technostress \\
\hline Hung et al. 2011 & $\begin{array}{l}\text { Organisational } \\
\text { / mobile }\end{array}$ & Accessibility & $\begin{array}{l}\text { IT / mobile } \\
\text { stressors }\end{array}$ & $\begin{array}{l}\text { Job stress, reduced } \\
\text { productivity }\end{array}$ \\
\hline Hung et al. 2015 & $\begin{array}{l}\text { Organisational } \\
\text { / mobile }\end{array}$ & Accessibility & $\begin{array}{l}\text { IT / mobile } \\
\text { stressors }\end{array}$ & Reduced productivity \\
\hline Leung \& Zhang 2017 & Work/home & - & $\begin{array}{l}\text { IT use, } \\
\text { work/home } \\
\text { aspects }\end{array}$ & Technostress \\
\hline Hudiburg 1989 & Education & - & Increased IT use & Technostress \\
\hline Lee et al. 2014 & $\begin{array}{l}\text { Personal / } \\
\text { leisure: mobile }\end{array}$ & - & $\begin{array}{l}\text { Compulsive } \\
\text { mobile use }\end{array}$ & Technostress \\
\hline $\begin{array}{l}\text { Moody \& Galletta } \\
2015\end{array}$ & $\begin{array}{l}\text { Personal / } \\
\text { leisure: } \\
\text { websites }\end{array}$ & Information scent & - & Stress \\
\hline Tams et al. 2014 & $\begin{array}{l}\text { Personal / } \\
\text { leisure: game }\end{array}$ & Message notifications & - & Reduced performance \\
\hline
\end{tabular}

